ARTICLE

\title{
Identification and characterization of latency-associated peptide-expressing $\gamma \delta$ T cells
}

Rafael M. Rezende ${ }^{1}$, Andre P. da Cunha1, Chantal Kuhn¹, Stephen Rubino ${ }^{1}$, Hanane M'Hamdi1,2, Galina Gabriely ${ }^{1}$, Tyler Vandeventer ${ }^{1}$, Shirong Liu', Ron Cialic ${ }^{1}$, Natalia Pinheiro-Rosa ${ }^{3}$, Rafael P. Oliveira ${ }^{3}$, Jellert T. Gaublomme ${ }^{4,5}$, Nikolaus Obholzer ${ }^{6}$, James Kozubek ${ }^{6}$, Nathalie Pochet ${ }^{6,7}$, Ana M.C. Faria ${ }^{3}$ \& Howard L. Weiner ${ }^{1}$

$\gamma \delta$ T cells are a subset of lymphocytes specialized in protecting the host against pathogens and tumours. Here we describe a subset of regulatory $\gamma \delta$ T cells that express the latencyassociated peptide (LAP), a membrane-bound TGF- $\beta 1$. Thymic CD27+IFN- $\gamma+$ CCR9 + $\alpha_{4} \beta_{7}+\mathrm{TCR} \gamma \delta+$ cells migrate to the periphery, particularly to Peyer's patches and small intestine lamina propria, where they upregulate LAP, downregulate IFN- $\gamma$ via ATF-3 expression and acquire a regulatory phenotype. TCR $\gamma \delta+\mathrm{LAP}+$ cells express antigen presentation molecules and function as antigen presenting cells that induce CD4 + Foxp3 + regulatory $\mathrm{T}$ cells, although $\mathrm{TCR} \gamma \delta+\mathrm{LAP}+$ cells do not themselves express Foxp3. Identification of $\mathrm{TCR} \gamma \delta+\mathrm{LAP}+$ regulatory cells provides an avenue for understanding immune regulation and biologic processes linked to intestinal function and disease.

\footnotetext{
${ }^{1}$ Ann Romney Center for Neurologic Diseases, Brigham and Women's Hospital, Harvard Medical School, Boston, Massachusetts 02115, USA. ${ }^{2}$ Rheumatology Unit, Department of Medicine at Karolinska University Hospital, Karolinska Institute, Solna, Stockholm 17177, Sweden. ${ }^{3}$ Department of Biochemistry and Immunology, Institute of Biological Sciences, Federal University of Minas Gerais, Belo Horizonte 31.270-901, Brazil. ${ }^{4}$ Department of Chemistry and Chemical Biology, Harvard University, Cambridge, Massachusetts 02138, USA. ${ }^{5}$ Department of Physics, Harvard University, Cambridge, Massachusetts 02138, USA. ${ }^{6}$ Program in Translational NeuroPsychiatric Genomics, Institute for the Neurosciences, Departments of Neurology and Psychiatry, Brigham and Women's Hospital, Boston, Massachusetts 02115, USA. ${ }^{7}$ Broad Institute of Massachusetts Institute of Technology (MIT) and Harvard, Cambridge, Massachusetts 02142, USA. Correspondence and requests for materials should be addressed to H.L.W. (email: hweiner@rics.bwh.harvard.edu).
} 
G amma-delta $(\gamma \delta) \mathrm{T}$ cells are lymphocytes bearing a T-cell receptor composed of gamma and delta chains as opposed to alpha and beta chains found in conventional $\mathrm{CD} 4+/ \mathrm{CD} 8+\mathrm{T}$ cells. Despite comprising the majority of immune cells in niches associated with epithelial surfaces such as the intestine, only $1-2 \%$ of $\gamma \delta \mathrm{T}$ cells are present in secondary lymphoid tissues ${ }^{1} . \gamma \delta \mathrm{T}$ cells are considered the first line of defense against pathogens as they can rapidly respond to TCR signals in an MHC-independent manner ${ }^{2}$ and to pattern recognition receptor signals such as Toll-like receptors ${ }^{3}$. Upon activation, $\gamma \delta \mathrm{T}$ cells rapidly secrete IFN- $\gamma$ and IL-17 and acquire cytotoxic activity ${ }^{4-6}$. Two distinct $\gamma \delta$ T cell subsets have been described on the basis of their cytokine production profile. $\gamma \delta \mathrm{T} 1$ cells express $\mathrm{CD} 27$ and secrete IFN- $\gamma$ (ref. 7), whereas $\gamma \delta$ T17 cells are CD27-, express CCR6 and secrete IL-17 (ref. 6).

In addition to their physiologic functions, $\gamma \delta \mathrm{T}$ cells may participate in immunopathology, including autoimmune disease models such as experimental autoimmune encephalomyelitis (EAE) $)^{8}$ and arthritis ${ }^{9}$. As $\gamma \delta \mathrm{T}$ cells are particularly abundant in the intestinal mucosa, their participation in intestinal inflammation has also been described ${ }^{10,11}$. IL-17 $+\gamma \delta$ T cells play a crucial role in enhancing in vivo Th1 and Th17 differentiation and $\mathrm{T}$ cell-mediated colitis in mice ${ }^{10}$ and exacerbate intestinal inflammation induced by dysregulated immune homeostasis ${ }^{11}$.

$\gamma \delta \mathrm{T}$ cells have also been reported to have immunoregulatory function. For example, in inflammatory bowel disease models, $\gamma \delta$ T-cell-deficient mice develop spontaneous colitis and are susceptible to 2,4,6-trinitrobenzene sulfonic acid-induced colitis $^{12}$. Transfer of intraepithelial $\gamma \delta$ lymphocytes (IEL- $\gamma \delta$ ) ameliorates colitis in this model ${ }^{12}$. In dextran sodium sulfate (DSS)-induced colitis in mice, IEL- $\gamma \delta$ T cells help preserve the integrity of damaged epithelial surfaces by the localized delivery of keratinocyte growth factor, a potent intestinal epithelial cell mitogen $^{13}$. Furthermore, by secreting IL-22 as well as antimicrobial products in a retinoic acid-dependent fashion, $\gamma \delta \mathrm{T}$ cells play an important role in the attenuation of intestinal inflammation induced by DSS or Citrobacter rodentium infection in mice ${ }^{14}$. Oral tolerance, a physiologic process that helps maintain gut homeostasis to the daily challenge of microbiota and dietary antigens ${ }^{15}$ is impaired in mice depleted of $\gamma \delta \mathrm{T}$ cells or in $\gamma \delta$ T-cell-deficient mice ${ }^{16,17}$.

The mechanism(s) by which $\gamma \delta \mathrm{T}$ cells exert regulatory function is not well understood. Forkhead box p3 (Foxp3) expression is not observed in murine $\gamma \delta \mathrm{T}$ cells ex vivo though they may express Foxp3 in vitro when cultured in the presence of TGF- $\beta 1$ (ref. 18). There are low levels of Foxp3 expression in human $\gamma \delta \mathrm{T}$ cells that, like in mice, increase under Treg-inducing conditions in vitro ${ }^{18,19}$. Moreover, Rhodes et al. ${ }^{20}$ reported the existence of an IL-10 $+\gamma \delta \mathrm{T}$ cell subset that protected the liver from Listeria-induced, CD8 + $\mathrm{T}$-cell-mediated injury in mice. Interestingly, activated $\gamma \delta \mathrm{T}$ cells from cattle ${ }^{21}$, mice 22 and humans ${ }^{23}$ have been shown to express high levels of MHC-II and co-stimulatory molecules and function as antigen presenting cells (APCs). Although this APC-like function of $\gamma \delta \mathrm{T}$ cells has been associated with a more pro-inflammatory immune response ${ }^{24}$, it is possible that regulatory subtypes of $\gamma \delta \mathrm{T}$ cells may occur in vivo and have immunoregulatory function.

In the present study, we describe and characterize a subset of regulatory $\gamma \delta \mathrm{T}$ cells that are Foxp3 negative and express membrane-bound TGF- $\beta 1$ in the form of latencyassociated peptide (LAP). These cells function as APCs and possess the ability to induce Foxp3 in CD4 T cells in vitro and in vivo.

\section{Results}

Identification of a subset of LAP-expressing $\gamma \delta \mathrm{T}$ cells. Given our interest in the regulatory function of $\mathrm{T}$ cells, which express membrane-bound TGF- $\beta 1$ through its accessory-binding molecule LAP ${ }^{25,26}$, we investigated LAP expression on $\gamma \delta$ T cells. We found LAP-expressing $\gamma \delta$ T cells $(\mathrm{TCR} \gamma \delta+\mathrm{LAP}+)$ in several mouse lymphoid organs, particularly those from Peyer's patches (PPs) and small intestine lamina propria (SI-LP), where $\sim 20 \%$ of the $\gamma \delta \mathrm{T}$ cells were positive for this molecule (Fig. 1a,b; Supplementary Fig. 1a). Owing to the high cellularity in spleen, the absolute number of TCR $\gamma \delta+\mathrm{LAP}+$ cells in the spleen was greater than in the other organs investigated, followed by PPs (Fig. 1a). The absolute number of TCR $\gamma \delta+\mathrm{LAP}+$ cells in SI-LP was as low as in lymph nodes, thymus, large intestine lamina propria (LI-LP) and intraepithelial lymphocytes (Fig. 1a). There was minimal expression of LAP on $\gamma \delta \mathrm{T}$ cells from thymus, intraepithelial lymphocytes and LI-LP (Fig. 1a; Supplementary Fig. 1b). LAP was less expressed on other lymphoid cells in the PPs and SI-LP, such as CD4 and CD8 T cells, as compared with LAP expression on $\gamma \delta \mathrm{T}$ cells from these same organs (Fig. 1a; Supplementary Fig. 2a,b). We also detected LAP on $\gamma \delta$ T cells from human peripheral blood (Supplementary Fig. 3a,b), at comparable percentages found on splenic $\gamma \delta \mathrm{T}$ cells from mice. Because the highest frequency and absolute number of $\mathrm{TCR} \gamma \delta+\mathrm{LAP}+$ cells were found in PPs and spleen, respectively, we performed our characterization using TCR $\gamma \delta+\mathrm{LAP}+$ cells from these organs. Consistent with their LAP expression, mouse TCR $\gamma \delta+\mathrm{LAP}+$ cells expressed more TGF- $\beta 1$ than $\mathrm{TCR} \gamma \delta+\mathrm{LAP}-$ cells, as measured by messenger RNA (mRNA; Fig. 1c), and also expressed the cell-surface molecule Glycoprotein A Repetitions Predominant (GARP), which is known to bind and attach LAP to the cell surface ${ }^{27}$ (Fig. 1d). It has been reported that under Foxp3-induction conditions in vitro, both human and mice $\gamma \delta \mathrm{T}$ cells express Foxp3 (refs 18,19). However, Foxp3 was not detected ex vivo in non-manipulated naive mice ${ }^{18}$. Consistent with this, we found that $\gamma \delta \mathrm{T}$ cells from PPs and spleen of naive Foxp3-GFP mice did not express Foxp3 as measured either by mRNA or protein expression (Fig. 1e,f). $\mathrm{V} \gamma 1$ and $\mathrm{V} \gamma 4$ TCR chains were expressed on TCR $\gamma \delta+\mathrm{LAP}+$ and TCR $\gamma \delta+\mathrm{LAP}$ - cells, with $\mathrm{V} \gamma 1$ the most expressed in both cell populations (Fig. 1g,h; Supplementary Fig. 4; nomenclature based on Heilig and Tonegawa ${ }^{28}$ ). In summary, our results identify a subpopulation of $\gamma \delta$ T cells in mice that express LAP on their surface.

TCR $\gamma \delta+\mathrm{LAP}+$ cells induce Tregs and ameliorate colitis. As LAP expression confers regulatory function to CD4 and CD8 $\mathrm{T}$ cells ${ }^{25,26}$, we asked whether TCR $\gamma \delta+\mathrm{LAP}+$ cells had in vivo regulatory activity. Two models of colitis were used to address this question: the T-cell model of colitis induced by CD4 + CD45RBhigh cell transfer into immunodeficient mice ${ }^{29}$ (Fig. 2a); and the innate immune-mediated model of colitis induced by oral administration of the chemical compound DSS ${ }^{30}$ (Supplementary Fig. 6a). RAG-1-/- mice transferred with either $\mathrm{CD} 4+\mathrm{CD} 45 \mathrm{RBhigh}$ cells alone (control group) or together with TCR $\gamma \delta$ + LAP - cells began to exhibit signs of colitis as measured by body weight loss at 5 weeks after transfer. This was not observed when animals received $\mathrm{TCR} \gamma \delta+\mathrm{LAP}+$ cells (Fig. 2b). The experiment was terminated at 7 weeks at which time mice had lost $15 \%$ of their body weight. Consistent with the weight reduction, histological analyses showed more severe colonic and small intestine tissue ulceration and inflammatory cell infiltrate in control or TCR $\gamma \delta+\mathrm{LAP}-$ mice than $\mathrm{TCR} \gamma \delta+\mathrm{LAP}+$ cell-treated mice (Fig. 2c). Furthermore, mice transferred with TCR $\gamma \delta+\mathrm{LAP}+$ cells had less IL-6, TNF- $\alpha$, 
a

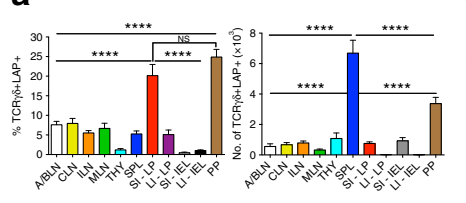

c

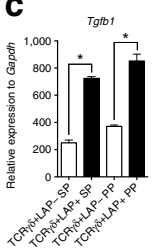

b

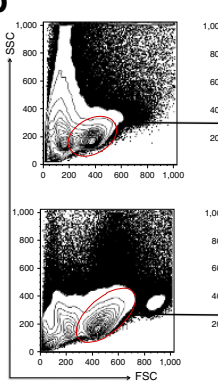

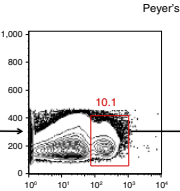
Peyer's patches

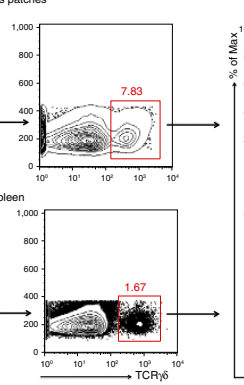

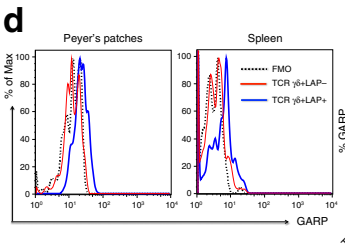
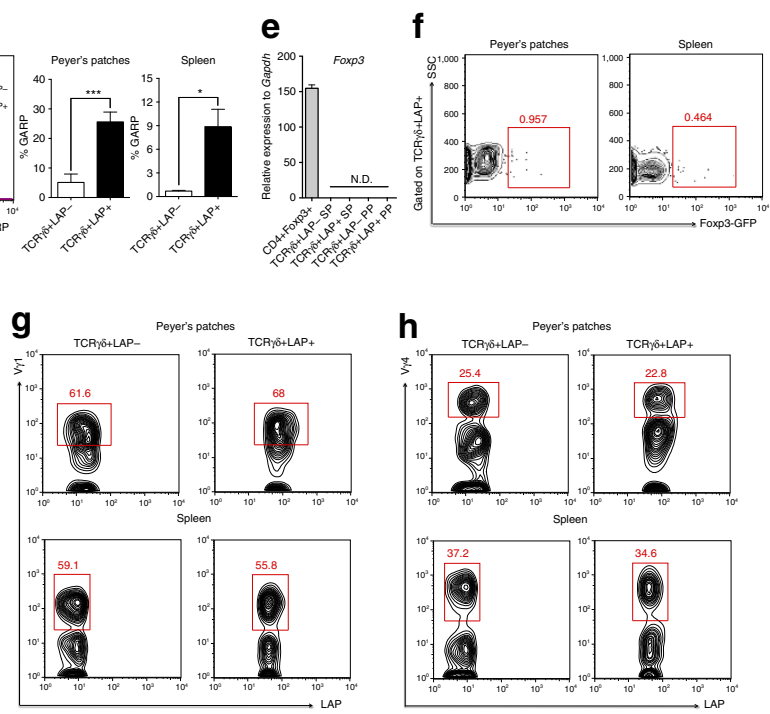

Figure $1 \mid \gamma \delta$ T cells express the latency-associated peptide (LAP), but not Foxp3. (a) Frequency and absolute number of $\gamma \delta$ T cells expressing LAP $(C D 3+\mathrm{TCR} \gamma \delta+)$ from axillary/brachial $(A / B L N)$, cervical $(C L N)$, inguinal (ILN), mesenteric (MLN) lymph nodes, thymus (THY), spleen (SPL), small (SI-LP) and large intestine (LI-LP) lamina propria, small (SI-IEL) and large intestine (LI-IEL) intraepithelial lymphocytes and Peyer's patches (PPs) from naive C57BL/6 mice $(n=15)$. These experiments were performed at least 20 times. (b) LAP-gating scheme in PPs and spleen. Cells were first incubated with an unconjugated anti-LAP antibody (clone TW7-16B4 or isotype control (IC) antibody) for 20 min to block LAP and then a conjugated anti-LAP antibody (same clone, TW7-16B4) was added to establish the specificity of LAP staining on $\gamma \delta$ T cells. (c) Quantitative RT-PCR analysis of Tgfb mRNAs from TCR $\gamma \delta+\mathrm{LAP}-$ and TCR $\gamma \delta+\mathrm{LAP}+$ cells (PP and spleen) of naive C57BL/ 6 mice ( $n=$ pooled cells from 10 mice per experiment). These data are representative of at least 3 independent experiments. (d) GARP expression on CD $3+$ TCR $\gamma \delta+\mathrm{LAP}-$ and CD $3+\mathrm{TCR} \gamma \delta+\mathrm{LAP}+$ cells from PP and spleen of naive C57BL/6 mice $(n=6)$. These data are representative of at least 3 independent experiments. (e) Quantitative RT-PCR analysis of Foxp3 mRNAs from CD3 $+\mathrm{TCR} \gamma \delta+\mathrm{LAP}-, \mathrm{CD} 3+\mathrm{TCR} \gamma \delta+\mathrm{LAP}+$ cells (PPs and spleen) and CD4 + Foxp3 + cells (Foxp3 positive control) of naive Foxp3-GFP mice $(n=$ pooled cells from 10 mice per experiment). These data are representative of at least five independent experiments. (f) Foxp3 expression in $\gamma \delta$ T cells $(\mathrm{CD} 3+\mathrm{TCR} \gamma \delta+\mathrm{LAP}+)$ from PPs and spleen of naive Foxp3-GFP mice $(n=6)$. These data are representative of at least five independent experiments. $(\mathbf{g}, \mathbf{h}) \vee \gamma 1(\mathbf{g})$ and $\vee \gamma 4(\mathbf{h})$ TCR chains expression on CD3 $+\mathrm{TCR} \gamma \delta+\mathrm{LAP}+$ cells from PP and spleen of naive C57BL/6 mice $(n=6)$. These data are representative of at least three independent experiments. Data are shown as mean \pm s.e.m. One-way analysis of variance (a) and Student's $t$-test (b,d) were used. ${ }^{\star} P<0.05,{ }^{\star \star} P<0.01,{ }^{\star \star \star} P<0.001,{ }^{\star \star \star \star} P<0.0001$.

IL-17A and IFN- $\gamma$ as well as CCL2 and CXCL10 (chemokines involved in the recruitment of myeloid and lymphoid cells to inflammatory sites) mRNA expression. Transfer of $\mathrm{TCR} \gamma \delta+\mathrm{LAP}+$ cells increased IL-10 and TGF- $\beta 1$ mRNA in the SI-LP as compared with control or TCR $\gamma \delta+\mathrm{LAP}-$ celltransferred animals (Fig. 2d). In the LI-LP, expression of IFN- $\gamma$ mRNA was decreased in TCR $\gamma \delta+\mathrm{LAP}+$ cell-treated mice compared with the other two groups, though IL-17A, CCL2 and CXCL10 mRNA levels were reduced in TCR $\gamma \delta+\mathrm{LAP}+$ cell-treated animals as compared with $\mathrm{TCR} \gamma \delta+\mathrm{LAP}-$ celltransferred mice, but were not different from the control group (Supplementary Fig. 5a). Foxp3 mRNA was upregulated in the SI-LP, but not in the LI-LP of TCR $\gamma \delta+\mathrm{LAP}+$ cell-treated mice (Fig. 2d; Supplementary Fig. 5a). Consistent with this, the frequency and absolute number of CD4 + Foxp $3+$ cells in the SI-LP were higher in mice treated with TCR $\gamma \delta+\mathrm{LAP}+$ cells (Fig. 2e). PP could not be investigated because RAG-1 - / - mice do not develop PP. Fluorescence-activated cell sorting (FACS) analysis demonstrated that the absolute number of total CD4 $\mathrm{T}$ cells and the frequency/absolute number of TCR $\gamma \delta+\mathrm{LAP}+$ cells were elevated compared with the LAP - counterpart in SILP, but not in LI-LP (Fig. 2f; Supplementary Fig. 5b). No differences were observed in either percentage or absolute number of total $\mathrm{CD} 4+$ and $\gamma \delta \mathrm{T}$ cells in the spleen (Supplementary Fig. 5c), though a significant increase of $\mathrm{CD} 4+$ Foxp $3+$ cells in $\mathrm{TCR} \gamma \delta+\mathrm{LAP}+$ cell-treated mice was observed (Supplementary Fig. 5d).

We also investigated TCR $\gamma \delta+\mathrm{LAP}+$ cells in the DSS-model, which is a $\mathrm{T}$ cell-independent model of colitis. Transfer of
$\mathrm{TCR} \gamma \delta+\mathrm{LAP}+$ cells ameliorated disease as measured by body weight with initial effects observed at day 6 and more prominent effects beginning at day 10 (Supplementary Fig. 6b). Thus there appears to be a combined effect on both disease progression and recovery. In addition, colonic length was not reduced in TCR $\gamma \delta+$ LAP + cell-treated mice (Supplementary Fig. 6c) and histological analysis showed less tissue ulceration and inflammatory cell infiltrate in mice transferred with TCR $\gamma \delta+\mathrm{LAP}+$ cells (Supplementary Fig. 6d). IFN- $\gamma$ mRNA was increased in LI-LP from TCR $\gamma \delta+\mathrm{LAP}+$ cell-treated mice (Supplementary Fig. 6e). These analyses were performed at day 14 after DSS treatment, which corresponds to the recovery phase of the colitis. Consistent with this, LI-LP from mice transferred TCR $\gamma \delta+\mathrm{LAP}+$ cells showed higher levels of IL-10 and TGF- $\beta 1$ mRNA, cytokines important for gut homeostasis, as well as IL-22, an interleukin involved in the protection of barrier surfaces, such as the gut epithelium $^{31}$ (Supplementary Fig. 6e). FACS analyses demonstrated that the absolute number of total $\mathrm{CD} 4 \mathrm{~T}$ cells and frequency/absolute number of CD4 + Foxp3 + cells were increased in the spleen of mice treated with TCR $\gamma \delta+\mathrm{LAP}+$ cells as compared with the other groups (Supplementary Fig. 6f). In PP, the absolute number of total CD4 and CD4 + Foxp3 + cells was increased in TCR $\gamma \delta+\mathrm{LAP}+$ cell-treated mice as compared with mice that received TCR $\gamma \delta+\mathrm{LAP}$ - cells, but was not different from naive or control groups (Supplementary Fig. 6g). In the LI-LP, TCR $\gamma \delta+\mathrm{LAP}-$ and TCR $\gamma \delta+\mathrm{LAP}+$ cell-treated mice had increased frequency and absolute number of total CD4 and CD4 + Foxp $3+$ cells, but were not different from each other (Supplementary Fig. 6h). 

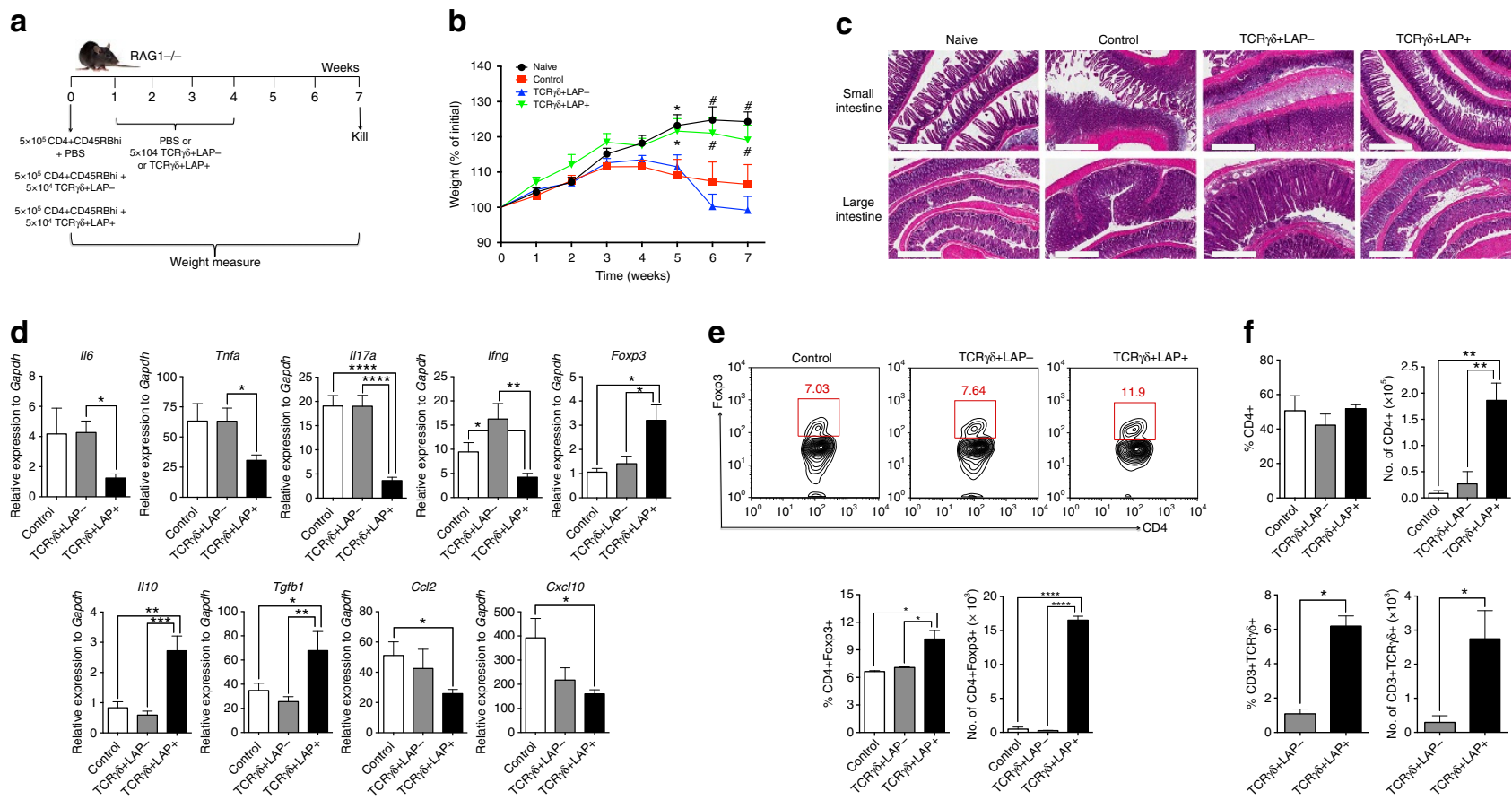

Figure 2 | TCR $\boldsymbol{\gamma} \boldsymbol{\delta}+\mathbf{L A P}+$ cells prevent CD4 + CD45RBhigh cell transfer-induced colitis in mice. (a) Schematic protocol of CD4 + CD45RBhigh cell transfer-induced colitis and $\gamma \delta$ T cell adoptive transfers. (b) Body weight (\% of initial weight) was measured throughout the experiment. Graph shows the mean \pm s.e.m. of naive, CD4 + CD 45RBhigh cell-treated only (Control) or together with CD3 + TCR $\gamma \delta+L A P-$ or CD3 + TCR $\gamma \delta+L A P+$ cells groups.

(c) Colons and small intestines were removed at week 7, and 5- $\mu \mathrm{m}$ serial sections were stained with haematoxylin-eosin. Magnification of $\times 40$. Scale bars, $600 \mu \mathrm{m}$. (d) Quantitative RT-PCR analysis of pro-inflammatory and anti-inflammatory cytokine mRNAs from SI-LP of cell transfer-induced colitis mice. These data are representative of three independent experiments. (e,f) FACS plots, frequency and absolute number of Foxp3 expression in transferred CD4 T cells (e) and frequency and absolute number of total transferred CD 4 T cells as well as total transferred CD3 + TCR $\gamma \delta+$ cells $(\mathbf{f})$ in SI-LP of cell transfer-induced colitis mice. These data are representative of three independent experiments. Data are shown as mean \pm s.e.m. $(n=9$ for naive; $n=15$ for control and TCR $\gamma \delta+$ LAP - groups; $n=9$ for TCR $\gamma \delta+$ LAP + group). Two-way analysis of variance (ANOVA) (b) and one-way ANOVA followed by Tukey multiple comparisons (d-f) were used. ${ }^{*}$, statistically different from control group; \#, statistically different from both control and TCR $\gamma \delta+$ LAP groups $(P<0.05)$. ${ }^{\star} P<0.05,{ }^{\star \star} P<0.01,{ }^{\star \star \star} P<0.001,{ }^{\star \star \star \star} P<0.0001$.

To investigate whether TCR $\gamma \delta+\mathrm{LAP}+$ cells had suppressive properties in vitro, we sorted naive CD4 + T cells from Foxp3GFP mice and stimulated them with anti-CD3 $\varepsilon$ in the presence of $\mathrm{TCR} \gamma \delta+\mathrm{LAP}-$ or TCR $\gamma \delta+\mathrm{LAP}+$ cells from WT mice plus antigen presenting cells (APCs). As a control, nTregs were tested. We found that neither TCR $\gamma \delta+\mathrm{LAP}+$ nor TCR $\gamma \delta+\mathrm{LAP}-$ cells were suppressive in vitro as compared with nTreg cells. Instead, TCR $\gamma \delta+\mathrm{LAP}+$ cells induced higher proliferation than control or TCR $\gamma \delta+\mathrm{LAP}-$ cells even at a $1: 8$ responder:TCR $\gamma \delta+\mathrm{LAP}+$ cell ratio (Supplementary Fig. 7a,b). Furthermore, no Foxp3 induction in responder cells was observed when either $\mathrm{TCR} \gamma \delta+\mathrm{LAP}+$ or $\mathrm{TCR} \gamma \delta+\mathrm{LAP}-$ cells were added to the culture as compared with the Foxp3 induction by nTreg cells (Supplementary Fig. 7c,d). Consistent with this, $\mathrm{TCR} \gamma \delta+\mathrm{LAP}+$ cells stimulated in vitro with plate-bound anti$\mathrm{CD} 3 \varepsilon$ and anti-CD28 acquired a pro-inflammatory profile with less TGF- $\beta 1$ and more TNF- $\alpha$ mRNA expression (Supplementary Fig. 8a,b). To further investigate whether TCR $\gamma \delta+\mathrm{LAP}+$ cells had suppressive properties in vitro and to determine whether the activation of TCR $\gamma \delta+$ LAP + cells by anti-CD $3 \varepsilon$ was associated with their inability to induce CD4 + Foxp $3+$ cells in vitro, we sorted naive CD4 T cells from 2D2xFoxp3-GFP mice (2D2 are $\mathrm{MOG}_{35-55}$-specific TCR transgenic animals) and stimulated them with $\mathrm{MOG}_{35-55}$ peptide in the presence of TCR $\gamma \delta+\mathrm{LAP}-$ or $\mathrm{TCR} \gamma \delta+\mathrm{LAP}+$ cells from wild-type (WT) mice in the absence of APCs. This allowed us to stimulate CD4 $+\mathrm{T}$ cells with MOG peptide and to assess the APC function of TCR $\gamma \delta+\mathrm{LAP}+$ without stimulating $\gamma \delta \mathrm{T}$ cells with anti-CD3$\varepsilon$ as we did above.
We found that $\mathrm{TCR} \gamma \delta+\mathrm{LAP}+$ but not $\mathrm{TCR} \gamma \delta+\mathrm{LAP}-$ cells induced both proliferation and Foxp3 expression in CD4 T cells (Supplementary Fig. 8c,d). Thus, when TCR $\gamma \delta+\mathrm{LAP}+$ cells are not stimulated by anti-CD3 $\varepsilon$ in vitro, they are able to induce CD4 + Foxp3 + Treg cells as they do in vivo. Moreover, because we did not add APCs to the co-culture, these results suggest that $\mathrm{TCR} \gamma \delta+\mathrm{LAP}+$ cells functioned as APCs and provided costimulatory signals to the naive $\mathrm{CD} 4+\mathrm{T}$ cells (Supplementary Fig. $8 c, d$ ). In summary, we found that in vivo TCR $\gamma \delta+\mathrm{LAP}+$ cells ameliorate colitis by promoting the induction of Foxp3 Treg cells. In vitro experiments demonstrate that they do not have direct regulatory function, but indirectly induce Tregs through their APC properties.

Antigen presenting cell function of TCR $\gamma \delta+L A P+$ cells. To further characterize TCR $\gamma \delta+\mathrm{LAP}+$ cells, we performed RNASeq of both TCR $\gamma \delta+\mathrm{LAP}+$ and TCR $\gamma \delta+\mathrm{LAP}-$ cells (Table 1; Supplementary Data 1 and Supplementary Data 2). We identified a signature of 407 genes that were enriched in TCR $\gamma \delta+\mathrm{LAP}+$ versus TCR $\gamma \delta+\mathrm{LAP}-$ cells with $P<0.05$. Among the upregulated genes, we found increased expression of genes related to antigen presentation, including MHC class II molecules (H2-Aa, $\mathrm{H} 2-\mathrm{Ab} 1, \mathrm{H} 2-\mathrm{Eb} 1$ and $\mathrm{H} 2-\mathrm{Eb} 2), \mathrm{CD} 40$ and CD86. We confirmed the expression of these APC-associated molecules on TCR $\gamma \delta+$ LAP + cells by flow cytometry (Fig. 3). Thymic $\gamma \delta \mathrm{T} 1$ cells and TCR $\gamma \delta+$ LAP - cells from PPs expressed MHC-II, to a lesser extent CD86, but did not express CD40 (Fig. 3a-d). TCR $\gamma \delta+$ 


\begin{tabular}{|c|c|c|c|}
\hline Gene & LAP - & LAP + & $\begin{array}{c}\text { LAP }+/ \text { LAP }-\log 2 \\
\text { (fold change) }\end{array}$ \\
\hline Itgae & 57.640 & 150.950 & 1.389 \\
\hline Atf3 & 9.123 & 29.458 & 1.691 \\
\hline $\mathrm{Cd} 81$ & 5.272 & 17.706 & 1.748 \\
\hline Cd86 & 2.133 & 7.197 & 1.754 \\
\hline $\mathrm{Cd} 244$ & 9.620 & 33.830 & 1.815 \\
\hline Lag3 & 6.360 & 30.390 & 2.257 \\
\hline $\mathrm{H} 2-\mathrm{Eb} 2$ & 0.700 & 3.570 & 2.350 \\
\hline Cd83 & 2.939 & 15.285 & 2.379 \\
\hline H2-DMb1 & 1.143 & 7.794 & 2.769 \\
\hline H2-DMb2 & 1.398 & 9.625 & 2.783 \\
\hline Cd74 & 32.320 & 293.340 & 3.182 \\
\hline H2-Eb1 & 8.276 & 78.555 & 3.247 \\
\hline $\mathrm{H} 2-\mathrm{Ab} 1$ & 8.336 & 80.864 & 3.278 \\
\hline $\mathrm{H} 2-\mathrm{Aa}$ & 10.520 & 107.540 & 3.354 \\
\hline $\mathrm{Cd} 40$ & 0.190 & 2.18 & 3.540 \\
\hline Apoe & 8.640 & 108.030 & 3.645 \\
\hline Gzmb & 25.390 & 336.200 & 3.727 \\
\hline Gzma & 100.620 & $1,416.50$ & 3.815 \\
\hline
\end{tabular}

RNA-Seq expression analyses of upregulated genes in TCR $\gamma \delta+\mathrm{LAP}-$ and TCR $\gamma \delta+\mathrm{LAP}+$ cells with $P<0.05$.

LAP + cells from PPs had higher expression of MHC-II and CD86 than both thymic $\gamma \delta \mathrm{T} 1$ cells and TCR $\gamma \delta+$ LAP - cells. They also expressed CD40 (Fig. 3a-d). MHC-I was detected on all $\gamma \delta \mathrm{T}$ cells analysed (Fig. $3 \mathrm{a}-\mathrm{d}$ ).

To determine whether TCR $\gamma \delta+\mathrm{LAP}+$ cells could function as antigen presenting cells, we cultured TCR $\gamma \delta+\mathrm{LAP}+$ or TCR $\gamma \delta+$ LAP - cells with Alexa Fluor 488-conjugated ovalbumin (OVA). TCR $\gamma \delta+$ LAP + cells took up twice as much OVA as their LAP - counterparts (Fig. 4a). When $\mathrm{OVA}_{323-339}$ peptidepulsed TCR $\gamma \delta+\mathrm{LAP}+$ were cultured with naive CD $4+\mathrm{T}$ cells from OT-IIxFoxp3-GFP (OVA $323-339$-specific TCR transgenic) mice, we observed proliferation to a similar extent as with OVA $_{323-339}$ peptide-pulsed CD103 + CD11c + dendritic cells (DC; Fig. 4b). No proliferation was observed when TCR $\gamma \delta+$ LAP - cells were pulsed with $\mathrm{OVA}_{323-339}$ peptide and were cultured with CD4 + T cells (Fig. 4b).

The decreased proliferative response seen when $\mathrm{T}$ cells were cultured with CD103 + CD11c + DCs versus CD103 - CD11c + . DCs is consistent with their well-known tolerogenic properties and their ability to induce Foxp3 in CD $4+\mathrm{T}$ cells $^{32}$. We thus measured Foxp3 expression in naive CD $4+\mathrm{T}$ cells co-cultured with $\mathrm{OVA}_{323-339}$ peptide-loaded $\mathrm{TCR} \gamma \delta+\mathrm{LAP}+$ or TCR $\gamma \delta+$ LAP - cells. We found that TCR $\gamma \delta+\mathrm{LAP}+$ but not TCR $\gamma \delta+$ LAP - cells induced Foxp 3 expression in a fashion analogous to CD103 + CD11c + DCs (Fig. 4c). Because LAP has been reported to be important for Foxp3 induction in a cellcontact-dependent manner ${ }^{33}$, we investigated the requirement for LAP to induce Foxp 3 by TCR $\gamma \delta+\mathrm{LAP}+$ cells in vitro. Using a monoclonal anti-LAP antibody developed in our laboratory ${ }^{34}$, we found that the induction of Foxp3 in CD4 $\mathrm{T}$ cells by $\mathrm{TCR} \gamma \delta+\mathrm{LAP}+$ cells was reduced by three-fold when LAP was blocked (Fig. 4d). To investigate whether the proliferative activity and Foxp 3 induction by TCR $\gamma \delta+\mathrm{LAP}+$ cells were dependent on MHC-II, we sorted TCR $\gamma \delta+\mathrm{LAP}+$ cells from MHC-II - / - mice, pulsed them with $\mathrm{OVA}_{323-339}$ peptide, and co-cultured them with CellTrace Violet-labeled naive CD4 $+\mathrm{T}$ cells from OT-IIxFoxp3-GFP. We found that MHC-II $+/+$ but not MHC-II $-/-\mathrm{TCR} \gamma \delta+\mathrm{LAP}+$ cells pulsed with $\mathrm{OVA}_{323-339}$ peptide induced proliferation and Foxp3 expression in CD4
T cells (Fig. 4e,f). Thus, TCR $\gamma \delta+$ LAP + cells have MHC-II dependent APC properties.

To investigate whether TCR $\gamma \delta+\mathrm{LAP}+$ cells could promote proliferation and Foxp3 induction in CD4 T cells in vivo, we cotransferred CellTrace Violet-labeled naive CD4 $+\mathrm{T}$ cells from OT-IIxFoxp3-GFP mice with either TCR $\gamma \delta+\mathrm{LAP}+$ or TCR $\gamma \delta+$ LAP - cells pulsed with $\mathrm{OVA}_{323-339}$ peptide to WT recipient mice and measured proliferation and Foxp 3 expression in transferred CD4 $+\mathrm{T}$ cells 5 days later in the spleen. We found that both $\mathrm{OVA}_{323-339}$ peptide-pulsed $\mathrm{TCR} \gamma \delta+\mathrm{LAP}+$ and $\mathrm{TCR} \gamma \delta+\mathrm{LAP}-$ cells induced $\mathrm{CD} 4+\mathrm{T}$ cell proliferation in vivo, with greater proliferative activity induced by $\mathrm{TCR} \gamma \delta+$ LAP + cells (Supplementary Fig. 9a). In addition, TCR $\gamma \delta+$ LAP + cells induced more Foxp3 than their LAP - counterparts in vivo (Supplementary Fig. 9b). Thus, LAP-expressing $\gamma \delta$ T cells can function as APCs and induce CD4 + Foxp3 + cells in vivo.

TCR $\gamma \delta+$ LAP + cells arise from thymic $\gamma \delta$ T 1 cells. It has been shown that thymic $\gamma \delta$ T cells can be divided into two subpopulations: $\gamma \delta \mathrm{T} 1$ cells, characterized by the expression of CD27 and the production of IFN $-\gamma$ (ref. 7); and $\gamma \delta$ T17 cells, which are CD27 - ref. 7), express CCR6 and secrete IL-17 (ref. 6). Both subtypes are considered non-canonical $\gamma \delta \mathrm{T}$ cells and express $\mathrm{V} \gamma 1$ and $\mathrm{V} \gamma 4$ TCR chains $^{7}$, which is consistent with what we observed in TCR $\gamma \delta+\mathrm{LAP}+$ and $\mathrm{TCR} \gamma \delta+\mathrm{LAP}-$ cells (Fig. 1g,h; Supplementary Fig. 4). To determine which subset gives rise to TCR $\gamma \delta+\mathrm{LAP}+$ cells, we examined $\gamma \delta \mathrm{T}$ cells from PPs, the site where TCR $\gamma \delta+\mathrm{LAP}+$ cells are in the greatest abundance. We found the majority of $\gamma \delta \mathrm{T}$ cells in PPs were positive for CD27, but negative for CCR6 (Fig. 5a). Thus, most of $\mathrm{TCR} \gamma \delta+\mathrm{LAP}+($ as well as TCR $\gamma \delta+\mathrm{LAP}-)$ cells were $\gamma \delta \mathrm{T} 1$ cells (Fig. $5 \mathrm{a}$ ). Of note, $6-10 \%$ of thymic $\gamma \delta \mathrm{T}$ cells were $\gamma \delta \mathrm{T} 17$ cells as they were negative for CD27 and expressed CCR6 (Fig. 5b). When we examined LAP expression on $\gamma \delta$ T cells from CCR6 - / - mice, there was no difference compared with WT mice (Fig. 5c), suggesting that TCR $\gamma \delta+\mathrm{LAP}+$ cells arise from thymic $\gamma \delta \mathrm{T} 1$ cells. The expression of surface LAP on $\gamma \delta \mathrm{T}$ cells most likely occurs in the periphery because neither thymic $\gamma \delta \mathrm{T} 1$ nor $\gamma \delta \mathrm{T} 17$ cells expressed LAP on the surface (Fig. 5d). Intracellular LAP expression was detected in $15 \%$ of thymic $\gamma \delta \mathrm{T} 1$, but not in $\gamma \delta \mathrm{T} 17$ cells (Fig. 5e), indicating that LAP is intrathymically induced but only expressed on the cell surface in the periphery. As previously reported, thymic $\gamma \delta \mathrm{T} 1$ cells expressed IFN- $\gamma$, which increased after phorbol myristate acetate (PMA) and ionomycin (ION) stimulation, but virtually no IL17A (ref. 7). Because TCR $\gamma \delta+$ LAP + cells stimulated with PMA/ION downregulate LAP (Fig. 6a), we performed IFN- $\gamma$ and IL17A intracellular staining from fresh ex vivo $\gamma \delta \mathrm{T}$ cells from both thymus and PPs. Thymic $\gamma \delta$ T1 cells produced IFN- $\gamma$, but not IL17A (Fig. 6b). TCR $\gamma \delta+$ LAP + cells expressed less IFN- $\gamma$, at both protein and mRNA levels than either thymic $\gamma \delta \mathrm{T} 1$ or TCR $\gamma \delta+$ LAP - cells (Fig. 6c), suggesting that LAP-expressing $\gamma \delta \mathrm{T}$ cells downregulate IFN- $\gamma$. IL17A protein and mRNA expression, however, was not observed in either TCR $\gamma \delta+\mathrm{LAP}+$ or TCR $\gamma \delta+$ LAP $-\gamma \delta$ T cells (Fig. 6d). Taken together, these data indicate that thymic $\gamma \delta$ T 1 cells acquire surface LAP in the periphery where IFN- $\gamma$ is downregulated.

TCR $\gamma \delta+$ LAP + cells downregulate IFN- $\gamma$ through ATF-3. Our RNA-Seq data demonstrated that activating transcription factor 3 (ATF-3) was upregulated in TCR $\gamma \delta+\mathrm{LAP}+$ cells (Table 1; Supplementary Data 1 and Supplementary Data 2). We focused on ATF-3 because it relates directly to a potential mechanism by which IFN- $\gamma$ is downregulated in TCR $\gamma \delta+$ LAP + cells. ATF- 3 is a member of the ATF/CREB family of 
a

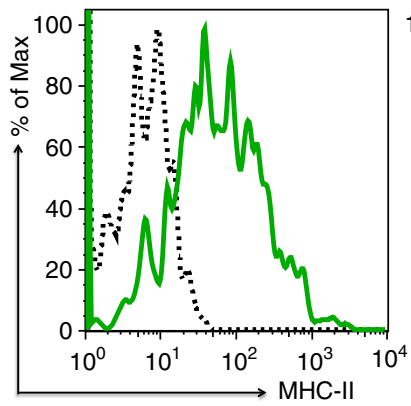

Thymus

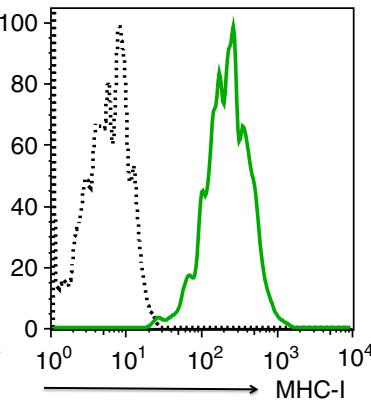

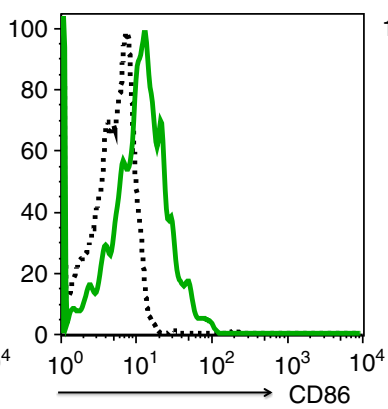

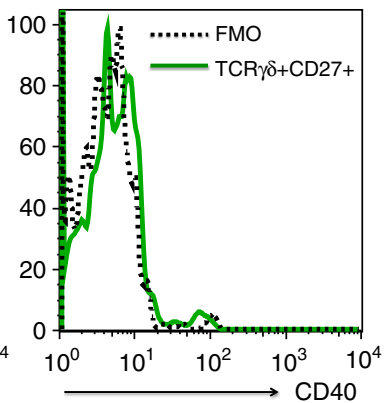

b

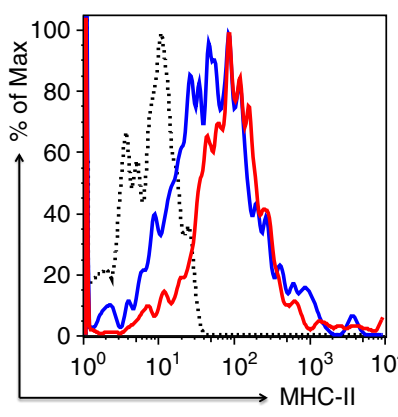

Peyer's patches
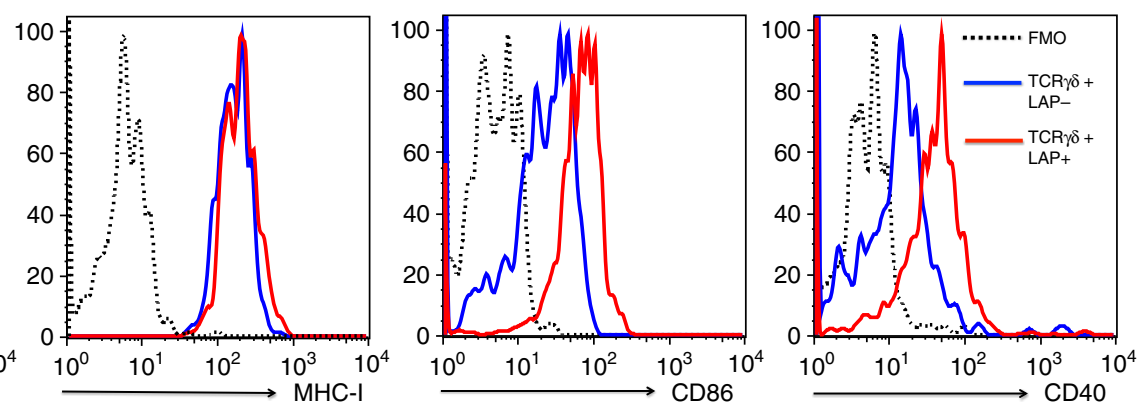

C

d
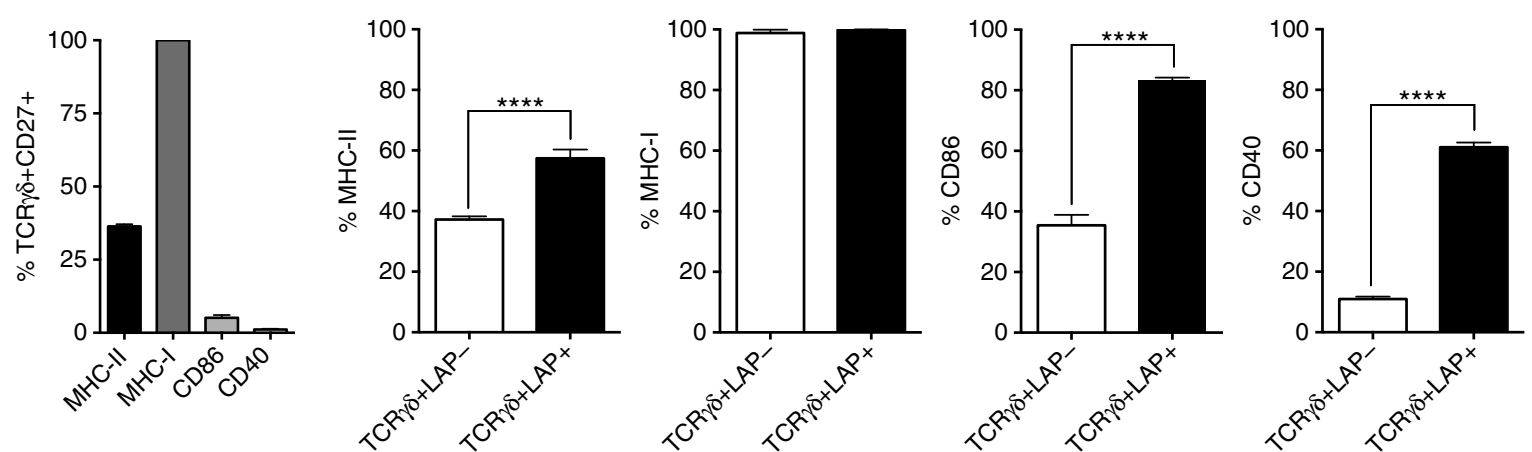

Figure 3 | Expression of antigen presentation-related molecules in $\boldsymbol{\gamma} \boldsymbol{\delta} \mathbf{T}$ cells. (a,b) MHC-II, MHC-I, CD86 and CD40 expression on $\gamma \delta \mathrm{T}$ cells from thymus $(\mathbf{a} ; \mathrm{CD} 3+\mathrm{TCR} \gamma \delta+\mathrm{CD} 27+)$ and PPs $(\mathbf{b} ; \mathrm{CD} 3+\mathrm{TCR} \gamma \delta+\mathrm{LAP}+)(n=9)$. (c,d) Frequency of MHC-II, MHC-I, CD86 and CD40 on $\gamma \delta$ T cells from thymus (c) and PPs (d). These data are representative of at least five independent experiments. Student's $t$-test was used. ${ }^{\star \star \star \star} P<0.0001$.

basic leucine zipper transcription factors that has been shown to negatively modulate IFN- $\gamma$ either indirectly by reducing cytokine production, including IL-12 (ref. 35), or directly by interacting with a cis-regulatory element of the IFN- $\gamma$ gene ${ }^{36}$. We confirmed increased expression of ATF3 in TCR $\gamma \delta+\mathrm{LAP}+$ cells by RTPCR (Fig. 6e). Consistent with this, we found that PP from ATF$3-/-$ mice had twice as many IFN- $\gamma$-producing $\mathrm{TCR} \gamma \delta+\mathrm{LAP}+$ cells than WT mice (Fig. 6f), suggesting that ATF-3 plays an important role in down-modulating IFN- $\gamma$ in $\mathrm{TCR} \gamma \delta+\mathrm{LAP}+$ cells.

Thymic $\gamma \delta \mathrm{T} 1$ cells are imprinted with gut-homing molecules. Because the highest percentage of TCR $\gamma \delta+\mathrm{LAP}+$ cells was found in PPs and SI-LP (Fig. 1a; Supplementary Fig. 1), we asked whether thymic $\gamma \delta \mathrm{T}$ cells expressed the CCL25 chemokine receptor CCR9 as well as the integrin $\alpha_{4} \beta_{7}$, which are considered gut-homing molecules ${ }^{37}$. We found that expression of CCR9 and $\alpha_{4} \beta_{7}$ was primarily detected on $\gamma \delta \mathrm{T} 1$ cells with lower expression on $\gamma \delta \mathrm{T} 17$ cells (Fig. $7 \mathrm{a}$ ). To further investigate the role of CCR9 and $\alpha_{4} \beta_{7}$ on homing of $\gamma \delta$ T cells to the gut, CCR9 $-/-$ and $\beta_{7}-/-$ mice were used and we found reduced frequency/ absolute number of $\gamma \delta \mathrm{T} 1$ and TCR $\gamma \delta+\mathrm{LAP}+$ cells in the PP (Fig. 7b). Because $\gamma \delta \mathrm{T} 1$ cells correspond to the majority of $\gamma \delta \mathrm{T}$ cells in the PP (Fig. 5a; Fig. 6b), the absolute number of total $\gamma \delta \mathrm{T}$ cells was also decreased (Fig. 7b). In association with the smaller $\gamma \delta \mathrm{T} 1$ and $\mathrm{TCR} \gamma \delta+\mathrm{LAP}+$ cell compartments in the gut of CCR9 $-/-$ and $\beta_{7}-/-$ mice, we found these $\gamma \delta$ T cell populations increased in the spleen of both CCR9 $-/-$ and $\beta_{7}-/-$ mice (Supplementary Fig. 10a). Consistent with the fact that CCR 9 and $\alpha_{4} \beta_{7}$ are expressed less on $\gamma \delta$ T17 than $\gamma \delta$ T1 cells, neither frequency nor absolute number of $\gamma \delta \mathrm{T} 17$ cells from CCR9 $-/-$ and $\beta_{7}-/-$ mice were altered in PPs, though number, but not percentage of these cells were increased in the spleen of CCR9 $-/-$ but not $\beta_{7}-/-$ mice (Fig. 7b; Supplementary Fig. 10a). To further confirm the gut-homing ability of $\gamma \delta \mathrm{T} 1$ cells, we transferred sorted thymic TCR $\gamma \delta+$ CD27 + cells from WT CD45.2 C57BL/6 mice to WT congenic CD 45.1 mice. We then tracked the CD $45.2+$ cells $36 \mathrm{~h}$ later and found higher frequency of these cells in PPs $(0.5 \%)$ than 

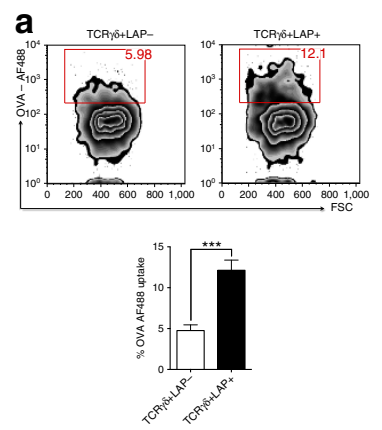
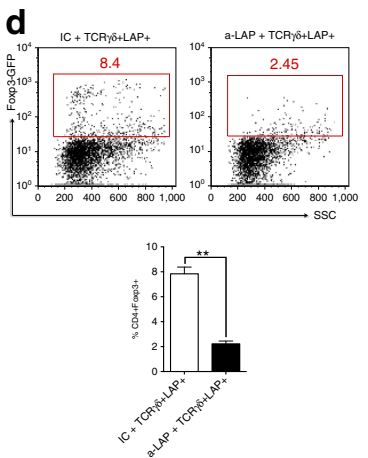

e
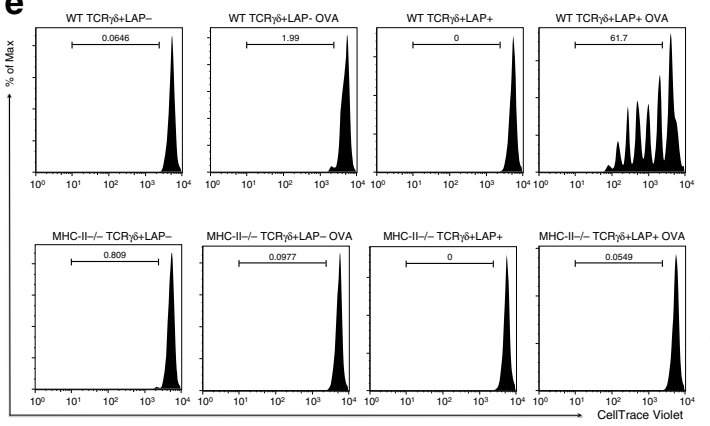

f
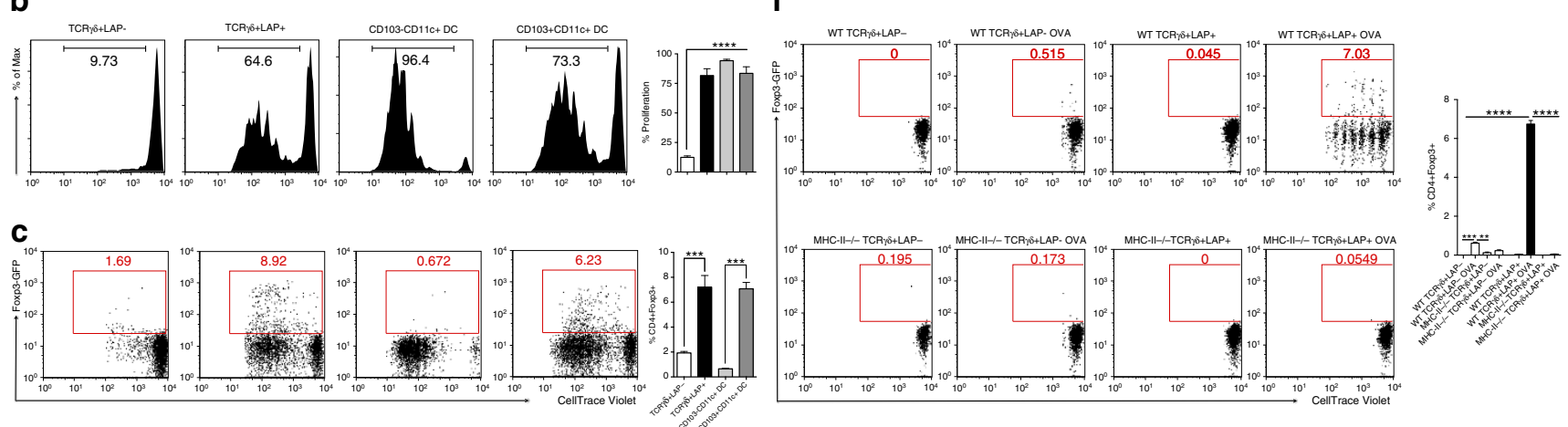

Figure 4 | TCR $\gamma \boldsymbol{\delta}+$ LAP + cells function as APCs and induce Foxp3 in CD4 T cells. (a) Soluble ovalbumin (OVA) coupled to Alexa Fluor 488 (OVA-AF488) endocytosis by $\mathrm{CD} 3+\mathrm{TCR} \gamma \delta+\mathrm{LAP}-$ or $\mathrm{CD} 3+\mathrm{TCR} \gamma \delta+\mathrm{LAP}+$ cells after $3 \mathrm{~h}$ of culture in vitro at $37^{\circ} \mathrm{C}(n=$ pooled cells from 10 mice per experiment). (b,c) Proliferation (b) and Foxp3 induction (c) in CellTrace Violet-stained naive CD4 T cells from OT-IlxFoxp3-GFP mice co-cultured with $\mathrm{OVA}_{323-339-l o a d e d} \mathrm{CD} 3+\mathrm{TCR} \gamma \delta+\mathrm{LAP}-, \mathrm{CD} 3+\mathrm{TCR} \gamma \delta+\mathrm{LAP}+, \mathrm{CD} 103-\mathrm{CD} 11 \mathrm{c}+$. or CD103 + CD11c + cells from WT C57BL/6 mice for 4 days at $37^{\circ} \mathrm{C}$ ( $n=$ pooled cells from 10 mice per experiment). (d) Foxp3 induction in CellTrace Violet-stained naive CD4 T cells from OT-IIxFoxp3-GFP mice cocultured with $\mathrm{OVA}_{323-339}$-loaded TCR $\gamma \delta+\mathrm{LAP}+$ cells from WT C57BL/6 mice in the presence or absence of $30 \mu \mathrm{g} \mathrm{ml} \mathrm{m}^{-1}$ of anti-LAP mAb for 4 days at $37^{\circ} \mathrm{C}$ ( $n=$ pooled cells from 10 mice per experiment). (e,f) Proliferation (e) and Foxp3 induction (f) in CellTrace Violet-stained naive CD4 T cells from OTIIxFoxp3-GFP mice co-cultured with OVA $323-339$-loaded (or not) CD3 + TCR $\gamma \delta+$ LAP - or CD3 + TCR $\delta$ + LAP + cells from either WT C57BL/6 or MHC$I I-/-$ mice for 4 days at $37^{\circ} \mathrm{C}(n=$ pooled cells from 10 mice per experiment). These data are representative of at least three independent experiments. One-way analysis of variance followed by Tukey multiple comparisons $(\mathbf{b}, \mathbf{e}, \mathbf{f})$ and Student's $t$-test $(\mathbf{a}, \mathbf{c}, \mathbf{d})$ were used. ${ }^{\star \star} P<0.01,{ }^{\star \star \star} P<0.001$,

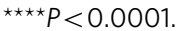
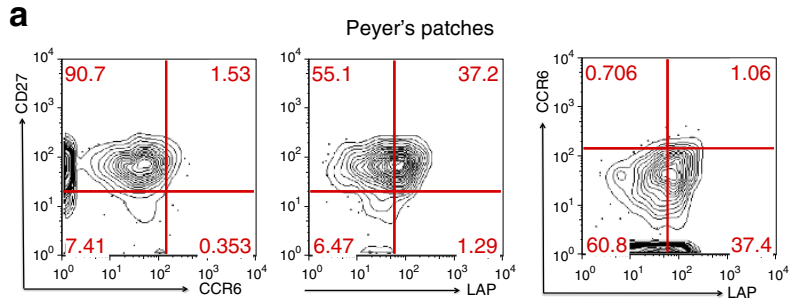
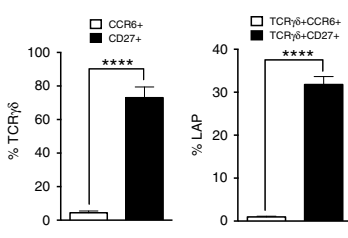

b

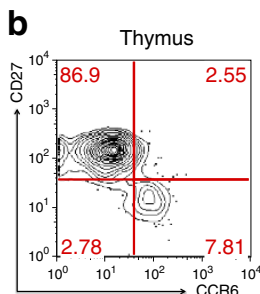

C

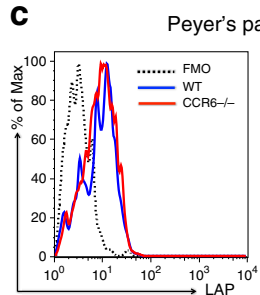

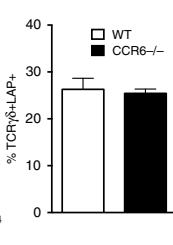

d

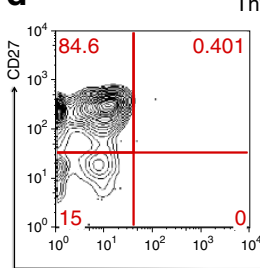

Thymus

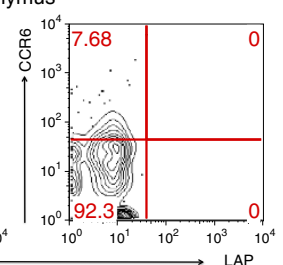

e

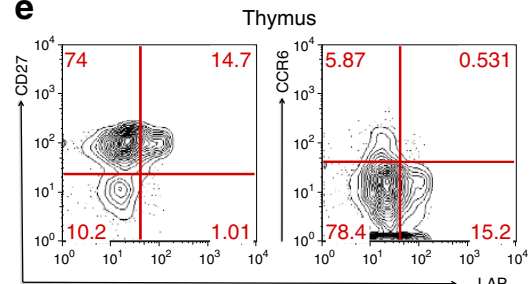

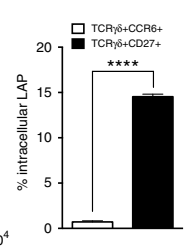

Figure $\mathbf{5} \mid \mathbf{T C R} \boldsymbol{\gamma} \boldsymbol{\delta}+\mathbf{L A P}+$ cells are originated from thymic $\boldsymbol{\gamma} \boldsymbol{\delta} \mathbf{T 1}$ cells. (a) CD27 and CCR6 expression on $\gamma \delta$ T cells (CD3 + TCR $\gamma \delta+)$ as well as expression of $\mathrm{LAP}$ on $\mathrm{CD} 3+\mathrm{TCR} \gamma \delta+\mathrm{CD} 27+$ and $\mathrm{CD} 3+\mathrm{TCR} \gamma \delta+\mathrm{CCR} 6+$ cells from PPs of naive C57BL/ 6 mice $(n=9)$. (b) CD27 and CCR6 expression on thymic $\gamma \delta$ T cells $(C D 3+$ TCR $\gamma \delta+)$ from naive C57BL/6 mice $(n=9)$. (c) LAP expression on $\gamma \delta$ T cells $(C D 3+$ TCR $\gamma \delta+)$ from WT and CCR6 $-/-$ mice ( $n=6$ per group). (d) Surface LAP expression on thymic CD3 $+\mathrm{TCR} \gamma \delta+$ and CD3 $+\mathrm{TCR} \gamma \delta+$ cells from naive C57BL/6 mice $(n=9)$.

(e) Intracellular LAP expression in thymic CD3 $+\mathrm{TCR} \gamma \delta+$ and CD3 $+\mathrm{TCR} \gamma \delta+$ cells from naive C57BL/ 6 mice. Cells were first incubated with purified anti-LAP (clone TW7-16B4) to block surface LAP and then fixed/permeabilized and labeled with PE-anti-LAP antibody $(n=6)$. These data are representative of at least three independent experiments. Data are shown as mean \pm s.e.m. Student's $t$-test was used. ${ }^{\star \star \star \star P} P<0.0001$. 

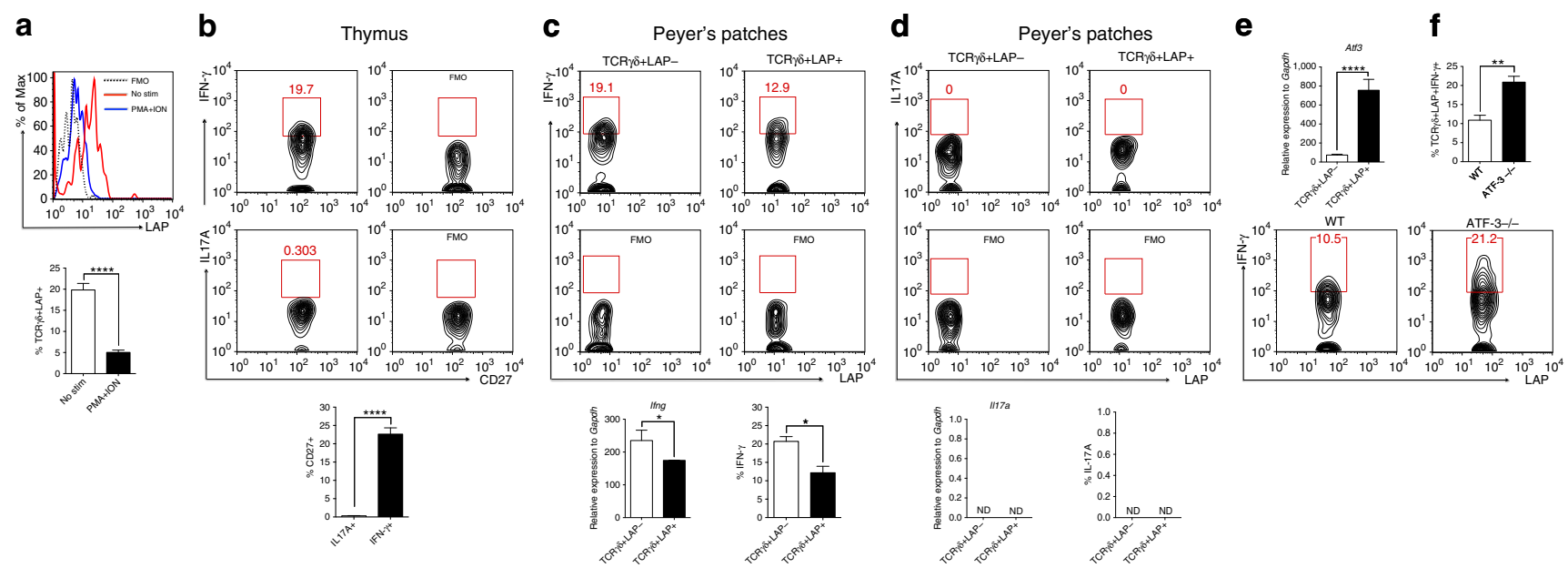

Figure 6 | IFN $-\boldsymbol{\gamma}$ is downregulated in TCR $\gamma \boldsymbol{\delta}+$ LAP + cells. (a) LAP expression on $\gamma \delta$ T cells $(C D 3+T C R \gamma \delta+)$ from PPs with and without PMA + ION stimulation $(n=6)$. (b-d) IFN- $\gamma$ and IL17A expression (protein and quantitative RT-PCR) in non-stimulated CD3 + TCR $\gamma \delta+$ CD27 + cells from thymus $(\mathbf{b})$ as well as $\mathrm{CD} 3+\mathrm{TCR} \gamma \delta+\mathrm{LAP}-$ and $\mathrm{CD} 3+\mathrm{TCR} \gamma \delta+\mathrm{LAP}+$ cells from PPs (c,d; $n=9 ; \mathrm{ND}=$ non-detected). These data are representative of at least three independent experiments. (e) Quantitative RT-PCR analysis of Atf3 mRNA from CD3 + TCR $\gamma \delta+\mathrm{LAP}-$ and CD3 + TCR $\gamma \delta+\mathrm{LAP}+$ cells $(n=$ pooled cells from 10 mice per experiment). (f) FACS plots and frequency of IFN- $\gamma$ expression in non-stimulated CD3 + TCR $\gamma \delta+L A P+$ cells from C57BL/ 6 WT or ATF-3 $-/-$ mice ( $n=9$ per group). These data are representative of at least three independent experiments. Data are shown as mean \pm s.e.m. Student's t-test was used. ${ }^{\star} P<0.05,{ }^{\star \star} P<0.01,{ }^{\star \star \star \star} P<0.0001$.

a

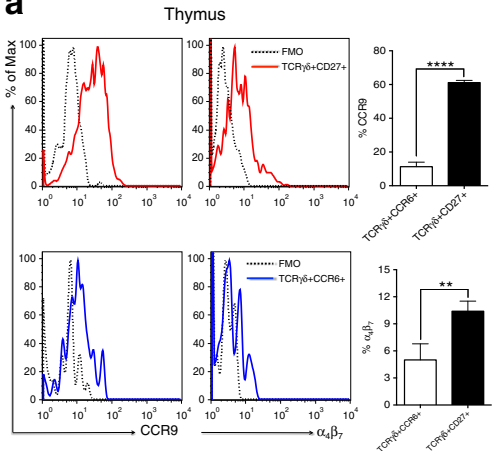

b
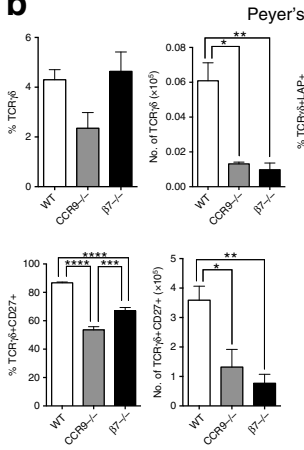

Peyer's patches
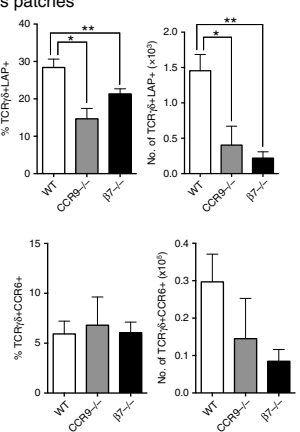

C
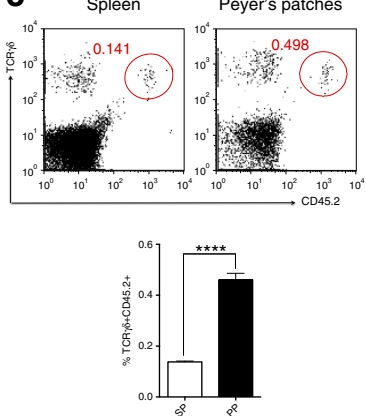

d
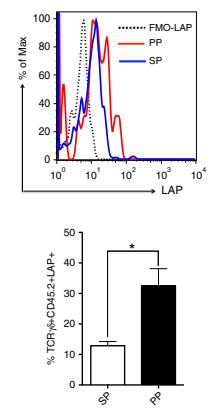

Figure 7 | Expression of gut-homing molecules on $\gamma \boldsymbol{\delta} \mathbf{T}$ cells. (a) CCR9 and $\alpha_{4} \beta_{7}$ expression on thymic $\gamma \delta$ T cells (CD3 + TCR $\gamma \delta+$ CD27 + and $\mathrm{CD} 3+\mathrm{TCR} \gamma \delta+\mathrm{CCR} 6+)$ from naive $\mathrm{C} 57 \mathrm{BL} / 6$ mice $(n=6)$. (b) Frequency and absolute number of total $\gamma \delta \mathrm{T}$ cells, CD3 $+\mathrm{TCR} \gamma \delta+\mathrm{CD} 27+$, $\mathrm{CD} 3+\mathrm{TCR} \gamma \delta+\mathrm{LAP}+$ and CD3 $+\mathrm{TCR} \gamma \delta+\mathrm{CCR} 6+$ cells from C57BL/6 WT, CCR9 $-/-$ and $\beta_{7}-/-$ mice in the PPs ( $n=5$ per group). (c) FACS plot and frequency of transferred CD $45.2+\mathrm{TCR} \gamma \delta+\mathrm{CD} 27+$ cells in the spleen and PPs of congenic CD45.1 mice $36 \mathrm{~h}$ after transfer $(n=3)$. $(\mathbf{d})$ Histogram and frequency of CD45.2 $+\mathrm{TCR} \gamma \delta+\mathrm{LAP}+$ cells in the spleen and PPs of congenic CD45.1 mice $36 \mathrm{~h}$ after transfer $(n=3)$. Data are shown as mean \pm s.e.m. One-way analysis of variance followed by Tukey multiple comparisons $(\mathbf{b})$ and Student's $t$-test $(\mathbf{a}, \mathbf{c}, \mathbf{d})$ were used. ${ }^{\star} P<0.05,{ }^{\star} \times<<0.01$, ${ }^{\star \star \star} P<0.001,{ }^{\star \star \star \star \star} P<0.0001$.

in spleen (0.15\%; Fig. 7c) Moreover, transferred CD45.2 $+\gamma \delta \mathrm{T}$ cells found in PPs expressed more LAP than splenic CD45.2 $+\gamma \delta$ $\mathrm{T}$ cells (Fig. 7d). Consistent with our observation that $\mathrm{TCR} \gamma \delta+\mathrm{LAP}+$ cells downregulate IFN- $\gamma$ (Fig. $6 \mathrm{~b}$ ), transferred CD $45.2+\mathrm{TCR} \gamma \delta+\mathrm{LAP}+$ cells had significantly less IFN- $\gamma$ than their LAP - counterpart (Supplementary Fig. 10b). Neither CD $45.2+\mathrm{TCR} \gamma \delta+\mathrm{LAP}-$ nor CD $45.2+\mathrm{TCR} \gamma \delta+\mathrm{LAP}+$ cells expressed IL-17A (Supplementary Fig. 10c). PMA + ION was not used to stimulate these cells, since, as shown in Fig. 5f, LAP cannot be detected under these conditions. Thus, gut-homing $\gamma \delta \mathrm{T} 1$ cells migrate to the periphery with preferential accumulation in the gut.

\section{Discussion}

Gamma-delta $(\gamma \delta) \mathrm{T}$ cells are a unique subset of lymphocytes which originate in the thymus after recombination activating gene (RAG)-mediated $\mathrm{V}(\mathrm{D}) \mathrm{J}$ rearrangement ${ }^{38} \cdot \gamma \delta \mathrm{T}$ cells are important in the immune response against pathogens and tumours $^{39}$ and are enriched in the skin and mucosal tissues ${ }^{40}$. In addition to their cytotoxic characteristics, regulatory functions of $\gamma \delta \mathrm{T}$ cells have been described, although they are not completely understood ${ }^{12,16,18-20,41}$. Of note, we found increased expression of GzmA and B in TCR $\gamma \delta+\mathrm{LAP}+$ cells suggesting that they may have cytotoxic properties, though this was not measured in our study. Foxp3 expression occurs in $\gamma \delta$ T cells stimulated in vitro and a subset of IL-10-producing $\gamma \delta$ T cells that protect mice liver from Listeria-elicited, CD8 T-mediated injury has been described ${ }^{20}$. Nonetheless, conflicting data have been reported in the literature regarding effector versus regulatory function of $\gamma \delta \mathrm{T}$ cells in models of disease in mice $8,10,20,42$. Here we describe a subset of regulatory $\gamma \delta$ T cells in mice that are Foxp3 negative and express LAP. We also observed $\mathrm{TCR} \gamma \delta+\mathrm{LAP}+$ cells in human peripheral blood. 
We found TCR $\gamma \delta+\mathrm{LAP}+$ cells throughout the immune system with highest expression in PPs and SI-LP. Both sites play an important role in defense against pathogens and the induction of immunological tolerance ${ }^{43}$. Because $\gamma \delta \mathrm{T}$ cells have been shown to respond quickly to microbial and non-microbial tissue perturbation $^{39}$, which is particularly important in highly antigenexposed sites, TCR $\gamma \delta+\mathrm{LAP}+$ cells may play a crucial role in gut homeostasis by providing a rapid regulatory response after encountering antigen. This is supported by the in vivo regulatory properties of TCR $\gamma \delta+\mathrm{LAP}+$ cells in the CD $4+\mathrm{CD} 45 \mathrm{RBhigh}$ cell transfer model of colitis $^{29}$. In this model, TCR $\gamma \delta+\mathrm{LAP}+$ cells decreased the inflammatory response caused by transferred CD4 $\mathrm{T}$ cells through reduction of pro-inflammatory cytokines such as IFN- $\gamma$, IL-17A, IL-6, TNF- $\alpha$, CCL2 and CXCL10 and increase of the anti-inflammatory cytokines IL-10 and TGF- $\beta 1$ mainly in the SI-LP. TCR $\gamma \delta+\mathrm{LAP}+$ cells induced proliferation and Foxp 3 expression in the transferred CD4 T cells in the SI-LP and spleen, but not in the LI-LP, suggesting that TCR $\gamma \delta+\mathrm{LAP}+$ cells preferentially migrate to the SI-LP, where they control colitis by increasing the Foxp3 + Treg cell compartment and by switching the intestinal milieu from an inflammatory to a regulatory one. Splenic TCR $\gamma \delta+\mathrm{LAP}+$ cells appear to play an important role in inducing CD4 + Foxp $3+$ cells and controlling colitis because, although there is a lower frequency of $\mathrm{TCR} \gamma \delta+\mathrm{LAP}+$ cells in the spleen, the absolute number of TCR $\gamma \delta+$ LAP + cells is 5 -fold more than in SI-LP. In the DSS model of colitis $^{30}$, transfer of TCR $\gamma \delta+\mathrm{LAP}+$ cells ameliorated disease. How $\mathrm{TCR} \gamma \delta+\mathrm{LAP}+$ cells exerted their regulatory activity in this model is not yet clear. In mice that were killed during the recovery phase of the colitis, we found differences in anti-inflammatory cytokines, such as IL-10 and TGF- $\beta 1$ as well as IL-22, an important interleukin involved in the promotion of antimicrobial immunity, inflammation and tissue repair at barrier surfaces $^{31}$. Of note, the mechanism by which DSS induces intestinal inflammation is believed to result from damage to the epithelial monolayer lining in the large intestine allowing the dissemination of pro-inflammatory intestinal contents (such as bacteria and their products) into underlying tissue ${ }^{44}$. Thus $\mathrm{TCR} \gamma \delta+\mathrm{LAP}+$ cells may control DSS-induced colitis by protecting gut epithelium. Furthermore, mice given $\mathrm{TCR} \gamma \delta+\mathrm{LAP}+$ cells had higher frequency and absolute cell number of CD4 + Foxp3 + cells in the spleen, but no difference was seen in the LI-LP, the DSS target site. It is possible that analysis of CD4 + Foxp $3+$ cells at earlier stages in the DSSinduced colitis model would show Treg cell expansion induced by $\mathrm{TCR} \gamma \delta+\mathrm{LAP}+$ cell treatment in the colonic lamina propria. Taken together, these data indicate that the regulatory effects induced by $\mathrm{TCR} \gamma \delta+\mathrm{LAP}+$ cells in DSS colitis is related to an increase of the Foxp $3+$ Treg cell compartment as well as production of anti-inflammatory and epithelium protective cytokines.

Suppressive activity of TCR $\gamma \delta+$ LAP + cells was not observed in a conventional in vitro suppression assay in which responder naïve $\mathrm{CD} 4 \mathrm{~T}$ cells were stimulated with anti-CD3 $\varepsilon$ in the presence of APCs. Under these conditions TCR $\gamma \delta+\mathrm{LAP}+$ cells induced proliferation of responder cells to a greater extent than TCR $\gamma \delta+$ LAP - cells or controls. Furthermore, contrary to what we observed in vivo, under these in vitro conditions, Foxp3 expression was not induced in responder cells, suggesting that the in vivo regulatory function of TCR $\gamma \delta+\mathrm{LAP}+$ cells involves more complex cell-cell interactions than in vitro. These data also suggest that $\mathrm{TCR} \gamma \delta+\mathrm{LAP}+$ cells acquire a pro-inflammatory phenotype following anti-CD3e stimulation in vitro. Consistent with this, we found that $\mathrm{TCR} \gamma \delta+\mathrm{LAP}+$ cells stimulated in vitro with plate-bound anti-CD3\&/anti-CD28 produced less TGF- $\beta 1$ and more TNF- $\alpha$ mRNA than freshly isolated
TCR $\gamma \delta+\mathrm{LAP}+$ cells. Accordingly, Foxp3 was induced when MOG specific CD4 + TCR Tg cells were cultured with freshly isolated $\mathrm{TCR} \gamma \delta+\mathrm{LAP}+$ cells. Thus, stimulation of $\mathrm{TCR} \gamma \delta+\mathrm{LAP}+$ cells with anti-CD3$\varepsilon$ impairs their ability to induce CD 4 + Foxp3 + cells, but does not affect their ability to induce proliferation of $\mathrm{CD} 4+\mathrm{T}$ cells. Foxp3 induction by $\mathrm{TCR} \gamma \delta+\mathrm{LAP}+$ cells was reversed by anti-LAP blocking antibody, indicating that induction of Foxp3 is mediated by LAP/TGF- $\beta 1$, analogous to the infectious tolerance induced by $\mathrm{CD} 4+$ Foxp $3+$ Treg cells which also relies on LAP/TGF- $\beta 1$ expression $^{33}$.

We found that $\mathrm{TCR} \gamma \delta+\mathrm{LAP}+$ cells upregulated antigen presentation-associated molecules including MHC-II, CD40 and CD86. Consistent with this, the APC-like function and Foxp3 induction capability of TCR $\gamma \delta+\mathrm{LAP}+$ cells were lost when $\mathrm{TCR} \gamma \delta+\mathrm{LAP}+$ cells from MHC-II $-/-$ mice were used. Of note, although TCR $\gamma \delta+$ LAP - cells did not induce proliferation in vitro, they did induce proliferation in vivo. This difference may be related to the activation of TCR $\gamma \delta+\mathrm{LAP}-$ cells in vivo, which in turn would increase the basal expression of antigen presentation molecules and enhance their APC function ${ }^{22,23}$. However, because TCR $\gamma \delta+\mathrm{LAP}-$ cells do not express LAP, they do not have regulatory properties.

We found that thymic $\gamma \delta \mathrm{T} 1(\mathrm{CD} 27+\mathrm{INF}-\gamma+)$ cells gave rise to both $\mathrm{TCR} \gamma \delta+\mathrm{LAP}+$ and $\mathrm{TCR} \gamma \delta+\mathrm{LAP}-$ cells. This is consistent with our observation that TCR $\gamma \delta+\mathrm{LAP}+$ and $\mathrm{TCR} \gamma \delta+\mathrm{LAP}$ - cells as well as $\gamma \delta \mathrm{T} 1$ cells expressed $\mathrm{V} \gamma 1$ and $\mathrm{V} \gamma 4$ TCR chains, a characteristic of non-canonical $\gamma \delta \mathrm{T}$ cells ${ }^{7}$. Intracellular LAP was detected in $15 \%$ of thymic $\gamma \delta \mathrm{T} 1$ cells and LAP was further upregulated after $\gamma \delta \mathrm{T} 1$ cells migrated from the thymus to the periphery, primarily to the gut (PPs and SI-LP). Because GARP, a glycoprotein known to bind and attach LAP to the cell surface ${ }^{27}$ was not detected on thymic $\gamma \delta \mathrm{T} 1$ cells, this may explain why thymic $\gamma \delta \mathrm{T} 1$ cells do not express surface LAP. Thymic $\gamma \delta$ T 1 cells expressed the gut-homing imprint molecules CCR9, the CCL25 chemokine receptor, and $\alpha_{4} \beta_{7}$ integrin, which binds to the mucosal addressin cell adhesion molecule-1 (MAdCAM-1) expressed on the high endothelial venules of the PPs and gut lamina propria ${ }^{45}$. When $\gamma \delta \mathrm{T} 1$ cells become $\mathrm{TCR} \gamma \delta+\mathrm{LAP}+$ cells, we observed downregulation of IFN- $\gamma$ an effect that may be mediated by ATF-3. ATF-3 is an adaptiveresponse gene ${ }^{46}$ and may modulate IFN- $\gamma$ production either indirectly by reducing the production of cytokines, such as IL-12 (ref. 35), or directly by targeting a cis-regulatory element in the IFN- $\gamma$ gene (at least in NK cells) ${ }^{36}$. We found that ATF-3 - / mice had higher expression of IFN- $\gamma$ in TCR $\gamma \delta+\mathrm{LAP}+$ cells, suggesting that ATF-3 may have a direct effect on IFN- $\gamma$ transcription in TCR $\gamma \delta+\mathrm{LAP}+$ cells, as IL-12 is not required for IFN- $\gamma$ expression in $\gamma \delta \mathrm{T}$ cells $\mathrm{s}^{7,47,48}$.

Our data suggest that thymic $\gamma \delta \mathrm{T} 1$ cells expressing CCR9 and $\alpha_{4} \beta_{7}$ integrin migrate to the gut, upregulate GARP and LAP, downregulate IFN- $\gamma$ via ATF-3 and acquire their APC properties. When TCR $\gamma \delta+\mathrm{LAP}+$ cells present antigen to a CD4 T cell, TGF- $\beta 1$ is released from LAP and induces Foxp3 in the CD4 T cell, rendering them regulatory. One of the major molecules that converts LAP to TGF- $\beta 1$ is thrombospondin-1 (TSP-1) ${ }^{49-51}$ TSP-1 is expressed in both naive and activated CD4 T cells ${ }^{52,53}$ and activates TGF- $\beta 1$ both in vitro and in vivo. Thus, the induction of Tregs by TCR $\gamma \delta+\mathrm{LAP}+$ cells appears to be an important physiologic mechanism by which TCR $\gamma \delta+\mathrm{LAP}+$ cells contribute to gut homeostasis.

In summary, our data identify TCR $\gamma \delta+\mathrm{LAP}+$ cells as a new subset of $\gamma \delta$ T cells with regulatory properties. The identification of TCR $\gamma \delta+\mathrm{LAP}+$ cells provides a new avenue for understanding immune regulation and biologic processes linked to intestinal function and disease. 


\section{Methods}

Mice. Male and female, 8-10-week-old and on a B6 genetic background mice were used in this study. C57BL/6 wild type, congenic CD45.1, RAG-1 - / - , CCR6 $-/-$, MHC-II $-/-$ and $\beta_{7}-/-$ mice were purchased from the Jackson Laboratory. CCR9 - / - mice were kindly provided by Dr Jesus Rivera-Nieves (University of California at San Diego-UCSD). ATF3 - / - , Foxp3-GFP, OT-IIxFoxp3-GFP and 2D2xFoxp3-GFP mice were housed in a conventional specific pathogen-free facility at the Harvard Institutes of Medicine according to the animal protocol with the full knowledge and permission of the Standing Committee on Animals at Harvard Medical School.

FACS and intracellular cytokine staining. A pool of cells from spleen and PPs or thymus of Foxp3-GFP and C57BL/6 mice was first enriched using CD4 microbeads (Foxp3-GFP) or TCR $\gamma \delta$ isolation kit (C57BL/6; all from Miltenyi Biotec). Naive (CD4 + CD62L + CD44-Foxp3 - and CD4 + Foxp3 + cells were sorted (FACS Aria II, BD Bioscience) with peridinin chlorophyll protein (PerCP)conjugated anti-CD4 (RM4-5; 1:250), allophycocyanin (APC)-conjugated antiCD62L (MEL-14; 1:250) and phycoerythrin (PE)-conjugated anti-CD44 (IM7; 1:500; all from BioLegend). CD4 + Foxp3 + cells were sorted on the basis of GFP expression. TCR $\gamma \delta+\mathrm{LAP}+$ and TCR $\gamma \delta+\mathrm{LAP}-\mathrm{T}$ cells were sorted with Alexa Fluor 700 (AF700)-conjugated anti-CD3e (eBio500A2; 1:100), APC-conjugated anti-TCR $\gamma \delta$ (eBioGL3; 1:100) and PE-conjugated anti-latency-associated peptide (LAP)/TGF- $\beta 1$ (TW7-16B4; $1: 50$; all from eBioscience). For TCR $\gamma \delta$ cell sorting, dead cells were excluded on the basis of 7 -AAD (1:25; BD Bioscience) staining. For intracellular cytokine staining, surface markers were stained for $25 \mathrm{~min}$ at $4{ }^{\circ} \mathrm{C}$ in $\mathrm{Mg}^{2+}$ and $\mathrm{Ca}^{2+}$ free HBSS with $2 \%$ FCS, 0.4\% EDTA $(0.5 \mathrm{M})$ and $2.5 \%$ HEPES $(1 \mathrm{M})$ then were fixed in Cytoperm/Cytofix (eBioscience), permeabilized with Perm/Wash Buffer (eBiosciences) and stained with PE-Cy7-anti-IFN- $\gamma$ (XMG1.2; 1:200) and FITC-anti-IL-17A (eBio17B7; 1:100; both from eBioscience) diluted in Perm/Wash buffer. In case of stimulation, the cells were stimulated for $4 \mathrm{~h}$ with PMA (phorbol 12-myristate 13-aceate; $50 \mathrm{ng} \mathrm{ml}^{-1}$; Sigma-Aldrich) and ionomycin $(1 \mu \mathrm{M}$; Sigma-Aldrich) and a protein-transport inhibitor containing monensin ( $1 \mu \mathrm{g} \mathrm{ml}^{-1}$ GolgiStop; BD Biosciences) before detection by staining with antibodies. Flow-cytometric acquisition was performed on an LSRII (BD Bioscience) by using DIVA software (BD Bioscience) and data were analysed with FlowJo software versions 9.6.4 (TreeStar Inc). To show specificity of LAP staining in Fig. 1 and Supplementary Figs 1 and 2, cells were first incubated with anti-LAP mAb (TW716B4 for mouse; kindly provided by Dr Takatoku Oida; TW4-2F8 for human) for $20 \mathrm{~min}$, washed and staining with surface markers, including either mouse Brilliant Violet 421 (BV421; TW7-16B4; 1:100) or human PE-anti-LAP (TW4-2F8; 1:100) antibodies. Other antibodies included: PerCP-anti-CD3e (1452C11; 1:100), PEanti- $\alpha_{4} \beta_{7}$ (DATK32; 1:100), eFluor450-anti-CCR9 (CW-1.2; 1:100), PE-anti-GARP (YGIC86; 1:100), PE-anti-TCR V $\gamma 2$ (UC3-10A6; 1:100), FITC-anti-CD27 (LG.7F9; 1:100), PE-anti-CD27 (LG.7F9; 1:100), PE-Cy7-anti-CCR6 (R6H1; 1:100), APCanti-CD45.2 (104; 1:100; all from eBioscience), Pacific Blue (PB)-anti-CD8a (53 6.7; 1:100), FITC-anti-TCRV $\gamma 1.1 / C r 4$ (2.11; 1:100), PE-Cy7-anti-I-A/I-E (M5/ 114.15.2; 1:200), PerCP-Cy5.5-anti-CD27 (LG.3A10; 1:100), PE-anti-CD103 (2E7; 1:100), FITC-anti-CD86 (GL-1; 1:100), FITC-anti-H-2Kb/H-2Db (28-8-6; 1:100; all from Biolegend), PE-anti-CD40 (3/23; 1:100; BD Bioscience).

Human peripheral blood mononuclear cell LAP staining. We collected blood from healthy controls (age 25-35 years) upon informed consent. Peripheral blood mononuclear cells were obtained by Ficoll density gradient and cells were stained with eFluor450-anti-CD3 (OKT3; 1:100), FITC-anti-TCR $\gamma \delta(B 1.1 ; 1: 100)$ and PEanti-LAP (TW4-2F8; 1:100) for flow cytometric analysis.

Purification and Cell transfer. Pooled cells from spleen and PPs or thymus of C57BL/ 6 mice were first enriched using CD 4 microbeads and TCR $\gamma \delta$ isolation kit (both from Miltenyi Biotec), as described above and then sorted. The purity of each population was $>98 \%$ as analysed by flow cytometry. To evaluate the immunomodulatory effect of TCR $\gamma \delta+\mathrm{LAP}+$ cells on DSS-induced colitis model, we transferred $1 \times 10^{5} \mathrm{TCR} \gamma \delta+\mathrm{LAP}-$ or TCR $\gamma \delta+\mathrm{LAP}+$ cells per animal intravenously. For the CD4 $+\mathrm{CD} 45 \mathrm{RBhigh}$ cell transfer-induced colitis model, we transferred $5 \times 10^{5} \mathrm{CD} 4+\mathrm{CD} 45 \mathrm{RBhigh}$ cells per animal intraperitoneally and $2.5 \times 10^{5} \mathrm{TCR} \gamma \delta+\mathrm{LAP}-$ or TCR $\gamma \delta+\mathrm{LAP}+$ cells per animal intravenously. For $\mathrm{CD} 45.2+\mathrm{TCR} \gamma \delta+\mathrm{CD} 27+$ cell transfer to CD 45.1 congenic mice, $1 \times 10^{6}$ cells per mouse intravenously were used. Intravenously and intraperitoneally, cell transfers were performed in 100 and $500 \mu$ of phosphate-buffered saline (PBS), respectively.

In vitro suppression assay. For suppression assays, sorted TCR $\gamma \delta+\mathrm{LAP}+$, TCR $\gamma \delta$ + LAP - or CD 4 + Foxp3 + cells were cultured at 1:1, 1:2, 1:4 and 1:8 ratio with syngeneic responder cells $(\mathrm{CD} 4+\mathrm{CD} 62 \mathrm{~L}+\mathrm{CD} 44-\mathrm{Foxp} 3-)$ previously stained with CellTrace Violet according to the manufacturers' recommendation (CellTrace Violet proliferation kit, Invitrogen). Cells were stimulated with antiCD3 $\varepsilon\left(1 \mu \mathrm{g} \mathrm{ml}^{-1} ; 145-2 \mathrm{C} 11\right.$, BioLegend) in the presence of mitomycin-treated $\left(50 \mu \mathrm{g} \mathrm{ml}^{-1}\right)$ APCs in $200 \mu \mathrm{l}$ of IMDM medium supplemented with $10 \%$ FBS in 96-well round-bottom plates. Proliferation and Foxp3 induction were assessed $72 \mathrm{~h}$ later by flow cytometry, based upon the dilution of the CellTrace violet dye.
In some experiments, naive cells from 2D2xFoxp3-GFP mice were sorted and co-cultured with sorted TCR $\gamma \delta+\mathrm{LAP}-$ or TCR $\gamma \delta+\mathrm{LAP}+$ cells from WT mice in the absence of APCs and stimulated with myelin oligodendrocyte glycoprotein (MOG $_{35-55}$ peptide, $20 \mu \mathrm{g} \mathrm{ml}^{-1}$ ) in $200 \mu \mathrm{l}$ of IMDM medium supplemented with $10 \%$ FBS in 96-well round-bottom plates. Proliferation and Foxp3 expression were assessed $72 \mathrm{~h}$ later by flow cytometry, based upon the dilution of the CellTrace violet dye and GFP expression, respectively.

In vitro activation of TCR $\gamma \delta$ + LAP - and TCR $\gamma \boldsymbol{\delta}+\mathbf{L A P}+$ cells. Sorted $\mathrm{TCR} \gamma \delta+\mathrm{LAP}-$ and TCR $\gamma \delta+\mathrm{LAP}+$ cells were incubated for 3 days at $37^{\circ} \mathrm{C}$ in the presence of plate-bound anti-CD3 and anti-CD28 $\left(1 \mu \mathrm{g} \mathrm{ml}{ }^{-1}\right.$ each). On the fourth day, RNA was extracted as described below in the real-time PCR section.

Uptake and presentation assays. $\mathrm{CD} 103+\mathrm{CD} 11 \mathrm{c}+, \mathrm{CD} 103-\mathrm{CD} 11 \mathrm{c}+$ dendritic cells and TCR $\gamma \delta+\mathrm{LAP}+$, TCR $\gamma \delta+\mathrm{LAP}-$ cells were first enriched using CD11c microbeads or TCR $\gamma \delta$ isolation kit (all from Miltenyi Biotec) and sorted. For uptake assay, TCR $\gamma \delta+\mathrm{LAP}-$ and TCR $\gamma \delta+\mathrm{LAP}+$ cells were incubated for $3 \mathrm{~h}$ at $37^{\circ} \mathrm{C}$ with $50 \mu \mathrm{g} \mathrm{ml}^{-1}$ of ovalbumin (OVA) coupled to Alexa Fluor 488 (Invitrogen) in a 96-well round-bottom plate. After incubation, cells were collected, thoroughly washed and analysed by flow cytometry. For presentation assay, sorted CD103-CD11c,+ CD103 + CD11c + dendritic cells and $\mathrm{TCR} \gamma \delta+\mathrm{LAP}+, \mathrm{TCR} \gamma \delta+\mathrm{LAP}-$ cells (from WT or MHC-II $-/$ - mice) were first incubated overnight at $37^{\circ} \mathrm{C}$ with $50 \mu \mathrm{g} \mathrm{ml}^{-1}$ of $\mathrm{OVA}_{323-339}$ peptide or medium only (unloaded cells as control) in a 96-well round-bottom plate. Next day, the cells were thoroughly washed and incubated at 1:1 ratio with sorted naive (CD4 + CD62L + CD44-Foxp3 - ) cells from OT-IIxFoxp3-GFP mice previously stained with CellTrace Violet dye (Invitrogen) for 4 days. Proliferation and Foxp 3 induction were then analysed by flow cytometry. In some experiments, purified anti-LAP mAb (TW7-16B4) was used to study the involvement of LAP in the Foxp 3 induction by TCR $\gamma \delta+\mathrm{LAP}+$ cells at a concentration of $30 \mu \mathrm{g} \mathrm{ml}^{-1}$.

In vivo presentation and Foxp3 induction assays. For the in vivo presentation and Foxp 3 induction study, sorted TCR $\gamma \delta+\mathrm{LAP}-$ or TCR $\gamma \delta+\mathrm{LAP}+$ cells from C57BL/6 mice were first loaded overnight with $50 \mu \mathrm{g} \mathrm{ml}^{-1}$ of $\mathrm{OVA}_{323-339}$ peptide (Invivogen) or medium only (unloaded cells as control), thoroughly washed, and $1 \times 10^{5}$ cells per animal were intravenously transferred together with $2 \times 10^{6}$ CellTrace Violet (Invitrogen)-stained naive CD4 T cells (CD4 + CD62L + CD44Foxp3 - from OT-IIxFoxp3-GFP mice) per animal in a volume of $100 \mu$ l. CellTrace violet staining was performed according to the manufacturers' recommendation. The mice were killed 5 days later and the spleens removed for FACS analysis.

Dextran sodium sulfate-induced colitis model. TCR $\gamma \delta+\mathrm{LAP}+$ and TCR $\gamma \delta+$ LAP - cells were sorted from C57BL/6 mice as described above and intravenously transferred to syngeneic mice at $5 \times 10^{4}$ cells per animal in $100 \mu \mathrm{l}$ of PBS at days 0 and 2 (Supplementary Fig. 6a). Colitis was induced by 3\% (w/v) dextran sodium sulfate (DSS; molecular weight $36-50 \mathrm{kDa}$; MP Biomedicals, LLC) added to the drinking water for 7 consecutive days. Mice were weighted every day until the end of the experiment (14 days). At day 14, the mice were killed and the colons were removed for length measurement, histological analysis, RT-PCR and FACS.

CD4 + CD45RBhigh cell transfer-induced colitis model. CD4 + CD25 CD45RBhigh cells were sorted from C57BL/6 mice using APC-anti-CD4 (GK1.5), PerCP-Cy5.5-anti-CD45RB (C363-16A) and FITC-anti-CD25 (PC61) and intraperitoneally transferred in syngeneic mice at $5 \times 10^{5}$ cells per animal in $500 \mu \mathrm{l}$ of PBS. Then TCR $\gamma \delta+\mathrm{LAP}+$ and TCR $\gamma \delta+\mathrm{LAP}-$ cells also sorted from C57BL/6 mice were intravenously transferred to the mice at $5 \times 10^{4}$ cells per animal in $100 \mu \mathrm{l}$ of PBS at the day of CD4 + CD25-CD45RBhigh cell transfer and once a week for the next 4 weeks (Fig. 2a). Mice weights were measured every week until the end of the experiment ( 7 weeks), when they were sacrificed and colons and small intestines removed for length measurement, histological analysis, RT-PCR and FACS as well as spleens removed for flow cytometric analyses.

Histopathology. Colons and/or small intestines were excised from animals at the end of both colitis experiments, flushed with PBS, cut longitudinally, rolled into 'Swiss rolls' and immediately fixed in formaldehyde $4 \%$ for $48 \mathrm{~h}$ and kept in ethanol $70 \%$. Samples were then embedded in paraffin and $5 \mu \mathrm{m}$ were cut and stained with haematoxylin and eosin. Sections were evaluated for histopathological changes, such as tissue integrity and inflammatory cells infiltration after being loaded into an Aperio ScanScope XT (Aperio), scanned via the semi-automated method and checked for image quality using visual inspection.

Real-time PCR. Naive CD4 + CD62L + CD44-Foxp3 - , CD4 + Foxp3 +, $\mathrm{TCR} \gamma \delta+\mathrm{LAP}+$ and TCR $\gamma \delta+\mathrm{LAP}-$ cells were sorted and RNA was extracted with a miRNeasy kit (Qiagen), then was reverse-transcribed with a high capacity cDNA reverse transcription kit (Applied Biosystems) and analysed by quantitative 
RT-PCR with a Vii 7 Real-time PCR system (Applied Biosystems) with the following primers and probes (from Applied Biosystems; identifier in parentheses) Tgfb1 (Mm00441724_m1), Ifng (Mm00801778_m1), Il17a (Mm00439619_m1), Atf3 (Mm00476032_m1), Foxp3 (Mm00475156_m1), Tnfa (Mm004433258_m1), Il6 (Mm00446191_m1), Il10 (Mm00439616_m1), Il22 (Mm00444241_m1), Ccl2 (Mm00441242_m1), Ccl5 (01302427_m1) and Cxcl10 (Mm00445235_m1). The comparative threshold cycle method and the internal control Gapdh (Mm99999915-g1) was used for normalization of the target genes.

\section{Expression analysis of TCR $\gamma \delta$ + LAP + versus TCR $\gamma \delta$ + LAP - cells using}

RNA-Seq. Total RNA samples were supplied to the Broad Institute's Genomics Platform and were QC'd by Agilent Bioanalyzer for RNA Integrity Scores (RIN >6), and normalized by Nanodrop to a minimum of $5 \mathrm{ng} \mathrm{\mu l}^{-1}$ and $250 \mathrm{ng}$. Libraries were constructed using Illumina's TruSeq kit with Poly A selection, pooled and sequenced on the Illumina HiSeq 2000 with 76 bp paired-end reads to a read coverage of $15 \mathrm{M}$ reads per sample.

After read preprocessing and GC bias removal, we processed our sequencing data using the latest Tuxedo RNA-Seq pipeline ${ }^{54}$, in particular, TopHat v2.0.11, Bowtie v2.2.2.0, and Cufflinks v2.2.1. We aligned our reads to mouse genome version GRCm38.p2 (mm10) with the Gencode GRCm38M2 gene set as annotation. Using Cuffdiffs traditional FPKM with a pooled replicate model, we generated signatures of differentially expressed genes for TCR $\gamma \delta+\mathrm{LAP}+$ versus TCR $\gamma \delta+\mathrm{LAP}$ - cells. In addition to Cuffdiff's significance measure, we chose to disregard low expression genes that did not have an arbitrary minimum absolute difference of 1 FPKM between expression values as cutoff to account for detection noise. Using these criteria, we identified a signature of 41 genes that were enriched specifically in TCR $\gamma \delta+\mathrm{LAP}+$ cell samples with $q<0.05$, while 407 genes were enriched in TCR $\gamma \delta+\mathrm{LAP}+$ cells with $P<0.05$. We used the likelihood function proposed by Trapnell et al..$^{55}$ and Roberts et al. ${ }^{56}$ to calculate $P$ and $q$ values. To remove 'infinity' values of log2-fold change for plotting, we added a constant of 0.001 to all the expression values and then recalculated the log2-fold-expression difference.

Statistics. GraphPad Prism 6.0 was used for statistical analysis (unpaired, twotailed Student's $t$-test or one-way analysis of variance, followed by Tukey multiple comparisons). For weight loss experiments, two-way analysis of variance was used. Differences were considered statistically significant with a $P$ value of less than 0.05 .

\section{References}

1. Girardi, M. Immunosurveillance and immunoregulation by gammadelta T cells. J. Invest. Dermatol. 126, 25-31 (2006).

2. Vantourout, P. \& Hayday, A. Six-of-the-best: unique contributions of gammadelta T cells to immunology. Nat. Rev. Immunol. 13, 88-100 (2013).

3. Wesch, D., Peters, C., Oberg, H. H., Pietschmann, K. \& Kabelitz, D. Modulation of gammadelta T cell responses by TLR ligands. Cell. Mol. Life Sci. 68, 2357-2370 (2011)

4. Ponomarev, E. D. \& Dittel, B. N. Gamma delta T cells regulate the extent and duration of inflammation in the central nervous system by a Fas liganddependent mechanism. J. Immunol. 174, 4678-4687 (2005).

5. Martin, B., Hirota, K., Cua, D. J., Stockinger, B. \& Veldhoen, M. Interleukin-17producing gammadelta $\mathrm{T}$ cells selectively expand in response to pathogen products and environmental signals. Immunity 31, 321-330 (2009).

6. Haas, J. D. et al. CCR6 and NK1.1 distinguish between IL-17A and IFNgamma-producing gammadelta effector T cells. Eur. J. Immunol. 39, 3488-3497 (2009)

7. Ribot, J. C. et al. CD27 is a thymic determinant of the balance between interferon-gamma - and interleukin 17-producing gammadelta $\mathrm{T}$ cell subsets. Nat. Immunol. 10, 427-436 (2009).

8. Petermann, F. et al. gammadelta T cells enhance autoimmunity by restraining regulatory $\mathrm{T}$ cell responses via an interleukin-23-dependent mechanism. Immunity 33, 351-363 (2010).

9. Roark, C. L. et al. Exacerbation of collagen-induced arthritis by oligoclonal, IL-17-producing gamma delta T cells. J. Immunol. 179, 5576-5583 (2007).

10. Do, J. S., Visperas, A., Dong, C., Baldwin, 3rd W. M. \& Min, B. Cutting edge: Generation of colitogenic Th17 CD4 T cells is enhanced by IL-17+ gammadelta T cells. J. Immunol. 186, 4546-4550 (2011).

11. Park, K. et al. TCR-mediated ThPOK induction promotes development of mature (CD24 - ) gammadelta thymocytes. EMBO J. 29, 2329-2341 (2010).

12. Inagaki-Ohara, $\mathrm{K}$. et al. Mucosal T cells bearing TCRgammadelta play a protective role in intestinal inflammation. J. Immunol. 173, 1390-1398 (2004).

13. Chen, Y., Chou, K., Fuchs, E., Havran, W. L. \& Boismenu, R. Protection of the intestinal mucosa by intraepithelial gamma delta T cells. Proc. Natl Acad. Sci. USA 99, 14338-14343 (2002).

14. Mielke, L. A. et al. Retinoic acid expression associates with enhanced IL-22 production by gammadelta $\mathrm{T}$ cells and innate lymphoid cells and attenuation of intestinal inflammation. J. Exp. Med. 210, 1117-1124 (2013).

15. Weiner, H. L., da Cunha, A. P., Quintana, F. \& Wu, H. Oral tolerance. Immunol. Rev. 241, 241-259 (2011).
16. Mengel, J. et al. Anti-gamma delta T cell antibody blocks the induction and maintenance of oral tolerance to ovalbumin in mice. Immunol. Lett. 48, 97-102 (1995).

17. Fujihashi, K. et al. gammadelta $\mathrm{T}$ cells regulate mucosally induced tolerance in a dose-dependent fashion. Int. Immunol. 11, 1907-1916 (1999).

18. Kang, N. et al. Identification and characterization of Foxp3(+) gammadelta $\mathrm{T}$ cells in mouse and human. Immunol. Lett. 125, 105-113 (2009).

19. Casetti, R. et al. Cutting edge: TGF-beta1 and IL-15 Induce FOXP3 + gammadelta regulatory $\mathrm{T}$ cells in the presence of antigen stimulation. J. Immunol. 183, 3574-3577 (2009).

20. Rhodes, K. A., Andrew, E. M., Newton, D. J., Tramonti, D. \& Carding, S. R. A subset of IL-10-producing gammadelta $\mathrm{T}$ cells protect the liver from Listeria-elicited, CD8(+) T cell-mediated injury. Eur. J. Immunol. 38, 2274-2283 (2008).

21. Collins, R. A. et al. Gammadelta T cells present antigen to CD4+ alphabeta T cells. J. Leukoc. Biol. 63, 707-714 (1998).

22. Cheng, L. et al. Mouse gammadelta T cells are capable of expressing MHC class II molecules, and of functioning as antigen-presenting cells. J. Neuroimmunol. 203, 3-11 (2008).

23. Brandes, M., Willimann, K. \& Moser, B. Professional antigen-presentation function by human gammadelta T Cells. Science 309, 264-268 (2005).

24. Hu, C. et al. Antigen-presenting effects of effector memory $\mathrm{V} \gamma 9 \mathrm{~V} \delta 2 \mathrm{~T}$ cells in rheumatoid arthritis. Cell. Mol. Immunol. 9, 245-254 (2011).

25. Ochi, H. et al. Oral CD3-specific antibody suppresses autoimmune encephalomyelitis by inducing CD $4+\mathrm{CD} 25-\mathrm{LAP}+\mathrm{T}$ cells. Nat. Med. 12, 627-635 (2006).

26. Chen, M. L., Yan, B. S., Kozoriz, D. \& Weiner, H. L. Novel CD8 + Treg suppress EAE by TGF-beta - and IFN-gamma-dependent mechanisms. Eur. J. Immunol. 39, 3423-3435 (2009).

27. Tran, D. Q. et al. GARP (LRRC32) is essential for the surface expression of latent TGF-beta on platelets and activated FOXP3 + regulatory T cells. Proc. Natl Acad. Sci. USA 106, 13445-13450 (2009).

28. Heilig, J. S. \& Tonegawa, S. Diversity of murine gamma genes and expression in fetal and adult T lymphocytes. Nature 322, 836-840 (1986).

29. Powrie, F. et al. Inhibition of Th1 responses prevents inflammatory bowel disease in scid mice reconstituted with CD45RBhi CD4 + T cells. Immunity $\mathbf{1}$, 553-562 (1994).

30. Dieleman, L. A. et al. Dextran sulfate sodium-induced colitis occurs in severe combined immunodeficient mice. Gastroenterology 107, 1643-1652 (1994).

31. Sonnenberg, G. F., Fouser, L. A. \& Artis, D. Border patrol: regulation of immunity, inflammation and tissue homeostasis at barrier surfaces by IL-22. Nat. Immunol. 12, 383-390 (2011).

32. Coombes, J. L. et al. A functionally specialized population of mucosal CD103+ DCs induces Foxp3 + regulatory T cells via a TGF-beta and retinoic aciddependent mechanism. J. Exp. Med. 204, 1757-1764 (2007).

33. Andersson, J. et al. CD4 + FoxP3 + regulatory T cells confer infectious tolerance in a TGF-beta-dependent manner. J. Exp. Med. 205, 1975-1981 (2008).

34. Oida, T. \& Weiner, H. L. TGF-beta induces surface LAP expression on murine CD4 T cells independent of Foxp3 induction. PLoS ONE 5, e15523 (2010).

35. Whitmore, M. M. et al. Negative regulation of TLR-signaling pathways by activating transcription factor-3. J. Immunol. 179, 3622-3630 (2007).

36. Rosenberger, C. M., Clark, A. E., Treuting, P. M., Johnson, C. D. \& Aderem, A. ATF3 regulates MCMV infection in mice by modulating IFN-gamma expression in natural killer cells. Proc. Natl Acad. Sci. USA 105, 2544-2549 (2008).

37. Iwata, M. et al. Retinoic acid imprints gut-homing specificity on $\mathrm{T}$ cells. Immunity 21, 527-538 (2004).

38. Kazen, A. R. \& Adams, E. J. Evolution of the V, D, and J gene segments used in the primate gammadelta T-cell receptor reveals a dichotomy of conservation and diversity. Proc. Natl Acad. Sci. USA 108, E332-E340 (2011).

39. Hayday, A. C. Gammadelta T cells and the lymphoid stress-surveillance response. Immunity 31, 184-196 (2009).

40. Hayday, A. C. [gamma][delta] cells: a right time and a right place for a conserved third way of protection. Annu. Rev. Immunol. 18, 975-1026 (2000).

41. Otsuka, A., Hanakawa, S., Miyachi, Y. \& Kabashima, K. CD39: a new surface marker of mouse regulatory gammadelta T cells. J. Allergy Clin. Immunol. 131, 1448-1451 (2013).

42. Huber, S. A., Graveline, D., Newell, M. K., Born, W. K. \& O’Brien, R. L. V gamma $1+\mathrm{T}$ cells suppress and $\mathrm{V}$ gamma $4+\mathrm{T}$ cells promote susceptibility to coxsackievirus B3-induced myocarditis in mice. J. Immunol. 165, 4174-4181 (2000).

43. Jung, C., Hugot, J. P. \& Barreau, F. Peyer's patches: the immune sensors of the intestine. Int. J. Inflam. 2010, 823710 (2010). 
44. Chassaing, B., Aitken, J. D., Malleshappa, M. \& Vijay-Kumar, M. Dextran sulfate sodium (DSS)-induced colitis in mice. Curr. Protoc. Immunol. 104, Unit 15.25 (2014)

45. Gorfu, G., Rivera-Nieves, J. \& Ley, K. Role of beta7 integrins in intestinal lymphocyte homing and retention. Curr. Mol. Med. 9, 836-850 (2009).

46. Hai, T., Wolford, C. C. \& Chang, A. Y.-S. ATF3, a hub of the cellular adaptiveresponse network, in the pathogenesis of diseases: is modulation of inflammation a unifying component? Gene Expr. 15, 1-11 (2010).

47. Jensen, K. D. et al. Thymic selection determines gammadelta T cell effector fate: antigen-naive cells make interleukin-17 and antigen-experienced cells make interferon gamma. Immunity 29, 90-100 (2008).

48. Turchinovich, G. \& Hayday, A. C. Skint-1 identifies a common molecular mechanism for the development of interferon-gamma-secreting versus interleukin-17-secreting gammadelta T cells. Immunity 35, 59-68 (2011).

49. Crawford, S. E. et al. Thrombospondin-1 is a major activator of TGF-betal in vivo. Cell 93, 1159-1170 (1998).

50. Schultz-Cherry, S., Lawler, J. \& Murphy-Ullrich, J. E. The type 1 repeats of thrombospondin 1 activate latent transforming growth factor-beta. J. Biol. Chem. 269, 26783-26788 (1994)

51. Schultz-Cherry, S., Ribeiro, S., Gentry, L. \& Murphy-Ullrich, J. E. Thrombospondin 1 binds and activates the small and large forms of latent transforming growth factor-beta in a chemically defined system. J. Biol. Chem. 269, 26775-26782 (1994).

52. Li, S. S. et al. T lymphocyte expression of thrombospondin-1 and adhesion to extracellular matrix components. Eur. J. Immunol. 32, 1069-1079 (2002).

53. Yang, K. et al. Deficiency of thrombospondin-1 reduces Th17 differentiation and attenuates experimental autoimmune encephalomyelitis. J. Autoimmun. 32, 94-103 (2009).

54. Trapnell, C. et al. Differential gene and transcript expression analysis of RNAseq experiments with TopHat and Cufflinks. Nat. Protoc. 7, 562-578 (2012).

55. Trapnell, C. et al. Transcript assembly and quantification by RNA-Seq reveals unannotated transcripts and isoform switching during cell differentiation. Nat. Biotechnol. 28, 511-515 (2010).

56. Roberts, A., Trapnell, C., Donaghey, J., Rinn, J. L. \& Pachter, L. Improving RNA-Seq expression estimates by correcting for fragment bias. Genome Biol. 12, R22 (2011).

\section{Acknowledgements}

This work was supported by the NIH (R01 AI43458 to H.L.W.) and Susan Furbacher Conroy Fellowship to A.P.C. We thank Deneen Kozoriz for her excellent technical support in cell sorting.

\section{Author contributions}

R.M.R. initiated the project, designed the experiments, carried out most of the experiments and wrote the manuscript. A.P.C. helped design and perform the experiments. H.M., G.G., T.V., S.L. and C.K. helped perform the experiments. N.P.R and R.P.O. initiated the project. R.C., J.T.G., N.O., J.K. and N.P. performed and analysed RNA-Seq experiments. A.M.C.F. provided input for the manuscript and H.L.W. supervised the experiments and the manuscript.

\section{Additional information}

Accession codes. GEO-NCBI (http://www.ncbi.nlm.nih.gov/geo/info/linking.html): GSE73077.

Supplementary Information accompanies this paper at http://www.nature.com/ naturecommunications

Competing financial interests: The authors declare no competing financial interests.

Reprints and permission information is available online at http://npg.nature.com/ reprintsandpermissions/

How to cite this article: Rezende, R. M. et al. Identification and characterization of latency-associated peptide-expressing $\gamma \delta$ T cells. Nat. Commun. 6:8726 doi: $10.1038 /$ ncomms9726 (2015).

\section{(c) (i)}

This work is licensed under a Creative Commons Attribution 4.0 International License. The images or other third party material in this article are included in the article's Creative Commons license, unless indicated otherwise in the credit line; if the material is not included under the Creative Commons license, users will need to obtain permission from the license holder to reproduce the material. To view a copy of this license, visit http://creativecommons.org/licenses/by/4.0/ 